\title{
An Adiabatic Solution Calorimeter and Measurements of a Standard Reaction for Solution Calorimetry
}

\author{
Edward J. Prosen and Marthada V. Kilday \\ Institute for Materials Research, National Bureau of Standards, Washington, D.C. 20234
}

(November 9, 1972)

This paper discusses in detail the design, construction, and performance of the vacuum jacketed, adiabatic solution calorimeter which was used for the work in the certification of two NBS Standard Reference Materials for solution calorimetry. As a test for the calorimetric precision the following enthalpies of reaction were measured (referred to the mass or moles of $\mathrm{H}_{2} \mathrm{SO}_{4} \cdot 8 \mathrm{H}_{2} \mathrm{O}$ ):

$$
\begin{gathered}
\mathrm{H}_{2} \mathrm{SO}_{4} \cdot 8 \mathrm{H}_{2} \mathrm{O}+2.36\left(\mathrm{NaOH} \cdot 2620 \mathrm{H}_{2} \mathrm{O}\right)=\left(\mathrm{Na}_{2} \mathrm{SO}_{4} \cdot 0.36 \mathrm{NaOH} \cdot 6193 \mathrm{H}_{2} \mathrm{O}\right)_{\text {soln }} \\
\Delta \mathrm{H}_{r}(298.15 \mathrm{~K})=-590.692 \pm 0.101 \mathrm{~J} \cdot \mathrm{g}^{-1} \\
=-34,194.1 \pm 5.9 \mathrm{cal} \cdot \mathrm{mol}^{-1} \\
\mathrm{H}_{2} \mathrm{SO}_{4} \cdot 8 \mathrm{H}_{2} \mathrm{O}+2.6\left(\mathrm{NaOH} \cdot 714 \mathrm{H}_{2} \mathrm{O}\right)=\left(\mathrm{Na}_{2} \mathrm{SO}_{4} \cdot 0.6 \mathrm{NaOH} \cdot 1866 \mathrm{H}_{2} \mathrm{O}\right)_{\mathrm{soln}} \\
\Delta \mathrm{H}_{r}(298.15 \mathrm{~K})=-590.828 \pm 0.193 \mathrm{~J} \cdot \mathrm{g}^{-1} \\
=-34,203.4 \pm 11.1 \mathrm{cal} \cdot \mathrm{mol}^{-1}
\end{gathered}
$$

Key words: Adiabatic solution calorimeter; enthalpy of reaction of $\mathrm{H}_{2} \mathrm{SO}_{4}$ in aqueous $\mathrm{NaOH}_{2} \mathrm{H}_{2} \mathrm{SO}_{4}$, enthalpy of reaction in $\mathrm{NaOH}(\mathrm{aq})$; heat of reaction of $\mathrm{H}_{2} \mathrm{SO}_{4}$ in aqueous $\mathrm{NaOH}$; heat of solution of $\mathrm{H}_{2} \mathrm{SO}_{4}$ in aqueous $\mathrm{NaOH}$; solution calorimetry; thermochemistry.

1. Introduction

2. General description of the calorimeter and procedures....... 180

3. The calorimeter in detail................................... 181

3.1. The vessel and its appendages....................... 181

a. The stirrer assembly.............................. 185

b. The vent and the wells............................ 186

c. The platinum sample holder....................... 186

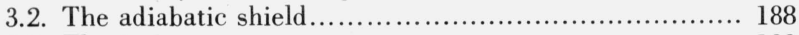

3.3. The jacket............................................ 189

3.4. The vacuum system and the hydraulic lift.............. 190

3.5. The calibrating heater and the control thermocouples ... 190

3.6. The electrical calibration and electronic control instruments.

3.7. The thermometers

\section{Introduction}

The construction of an adiabatic solution calorimeter began in 1962 in the Thermochemistry Section at the National Bureau of Standards. The calorimeter was to have the capability of measuring with high precision, enthalpies of solution of refactory materials in corrosive solutions, such as aqueous $\mathrm{HF}$, at temperatures as high as $363 \mathrm{~K}$. The first complete calorimetric
4. Procedures................................................ 195

4.1. Samples and solutions ................................. 195

4.2. Temperature measurements ............................ 195

4.3. Electrical calibrations................................... 196

5. Measurements of a standard reaction........................ 197

5.1. Sample and the solutions.............................. 198

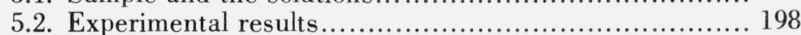

a. Temperature profiles for the adiabatic shield...... 199

b. Enthalpy of reaction of $\mathrm{H}_{2} \mathrm{SO}_{4} \cdot 8 \mathrm{H}_{2} \mathrm{O}$ with excess

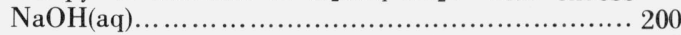

6. Other measurements........................................ 200

7. Conclusions................................................. 202

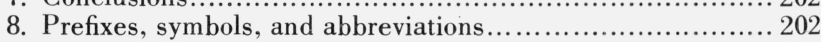

9. References

experiments were done near the end of 1964, and since that time many improvements have been made which increased the precision and accuracy of the measurements, and the dependability of the calorimetric system.

This calorimeter was used for the work which led to the certification of two NBS Standard Reference Materials for solution calorimetry, and it seemed appropriate to provide a detailed description of the calorimeter as documentation for that work as well as 
for other projects which will follow. Section 2 of this paper provides a general description of the calorimetric apparatus and procedures for those who are not interested in the great detail given in sections 3 and 4; these sections will interest those who are primarily concerned with details of construction and performance, and they have been written to benefit novices in calorimeter construction as well as teachers and students in calorimetry. Specific formulae and equations used for calculations have been given as an aid to other workers in this field. We have tried to answer many of the questions about the calorimeter posed by visitors to our laboratory and in some cases we have given the reasons for the choice of materials, instruments, or procedures.

Section 5 gives an example of measurements made with this calorimeter for a test reaction to indicate the precision of the calorimetric measurements.

\section{General Description of the Calorimeter and Procedures}

This adiabatic solution calorimeter operates in a 70-deg temperature range (293 to $363 \mathrm{~K}$ ); the solution capacity is $300 \pm 15 \mathrm{~cm}^{3}$; the maximum volume for liquid or solid samples in the platinum sample holder is $2.7 \mathrm{~cm}^{3}$; the electrical energy equivalent is approximately $1700 \mathrm{~J} \cdot \mathrm{K}^{-1}$ when the vessel contains 300 $\mathrm{cm}^{3}$ of $\mathrm{H}_{2} \mathrm{O}$, or approximately $450 \mathrm{~J} \cdot \mathrm{K}^{-1}$ when empty; the stirring speed can be changed from 200 to $850 \mathrm{rpm}$ in steps of 50 to $100 \mathrm{rpm}$; and a precision $(2 \mathrm{sdm})$ of \pm 0.02 percent has been achieved in measurements of the electrical energy equivalents and of some enthalpies of reaction. The calorimeter is capable of measuring the enthalpies of solution reactions which occur at atmospheric pressure between 293 and $363 \mathrm{~K}$ providing the chemicals involved do not attack platinum or react with the components of air. However, the calorimeter can be closed to allow gases other than air to be utilized.

A diagram of the calorimeter is shown in figure 1 . The vessel is silver, lined with platinum, and all parts in contact with the solution and its vapor are of platinum including the wells for the thermometer and for the calibrating heater, the stirrer, the sample holder, and five tubes (two are not shown) leading up from the cover which carry leads, etc., out of the calorimeter. The level of the solution is normally $0.5 \mathrm{~cm}$ below the cover of the vessel. The adiabatic shield is goldplated copper. Its temperature is controlled automatically by heaters on the external surface to follow the vessel temperature. The temperature difference between the cover of the vessel and the cover of the shield is sensed by a six-junction, copper-constantan thermocouple. During rating periods this temperature difference is less than $0.0001 \mathrm{~K}$. The nickel-plated copper jacket confines the vacuum which surrounds the vessel. The pressure in the system during calorimetric measurements is usually between 3 and $11 \times$ $10^{-2} \mathrm{~Pa}\left(2\right.$ and $\left.8 \times 10^{-4} \mathrm{~mm} \mathrm{Hg}\right)$.

Heat transfer from the calorimeter through the five tubes above the cover of the vessel is minimized by

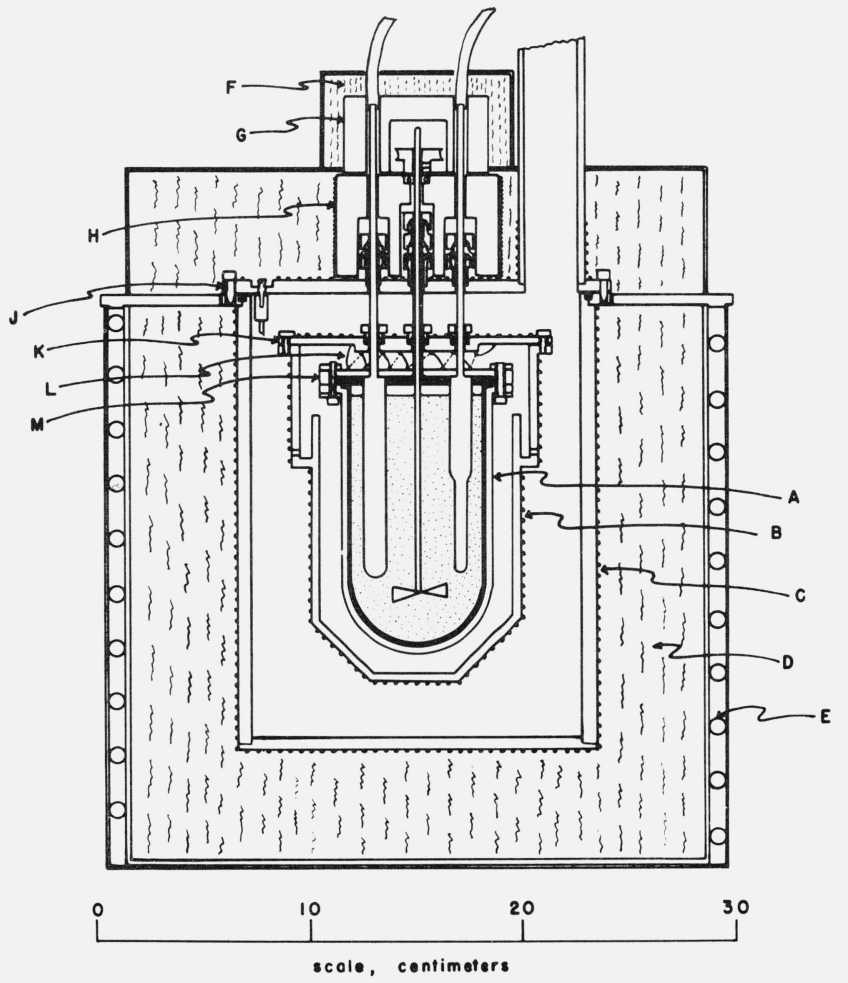

FigURE 1. Diagram of the adiabatic solution calorimeter.

(A) The vessel (silver, lined with platinum), (B) the adiabatic shield, (C) the constant temperature jacket. (D) the Fiberglas insulation, (E) the coil for circulation of cold water in experiments below room temperature, $(\mathrm{F})$ the Styrofoam insulation, $(\mathrm{G})$ an aluminum block at ambient temperature, $(\mathrm{H})$ an aluminum block at controlled temperature, $(\mathrm{J})$ the jacket cover, $(\mathrm{K})$ the shield cover, $(\mathrm{L})$ the shield control thermocouples, and $(\mathrm{M})$ the vessel cover.

by two additional heaters which are controlled automatically to follow the shield temperature: the first is on an aluminum block surrounding the fittings above the jacket cover, and the second is on the external surface of the jacket cover. Both of these areas as well as the cover of the adiabatic shield are in good thermal contact with the five platinum tubes, thus they are essentially at the shield temperature before entering the calorimeter.

Figure 2 is a photograph of the calorimeter showing (at center) the three covers for the jacket, the adiabatic shield, and the vessel, with the heater well and sample holder (front), the stirrer, and the thermometer well (rear), suspended from the cover of the vessel. The sample holder shown here is the earliest design; the improved design will be discussed in detail in section 3.1a. Also shown in figure 2 is the jacket well which is surrounded by the calorimeter insulation (Fiberglas). This unit is raised by a hydraulic lift to form a vacuumtight seal with the jacket cover by means of the Buna-N rubber o-ring shown in the rim of the jacket well.

Approximately $3 \mathrm{~h}$ is the minimum time required for a single experiment from the time the calorimeter is assembled until the measurements are completed. The usual experiment involves measurements of four rating periods (20 to $30 \mathrm{~min}$ each); an initial electrical calibration occurs between the first and second rating periods, the chemical reaction occurs between the second and third rating periods, and a final elec- 


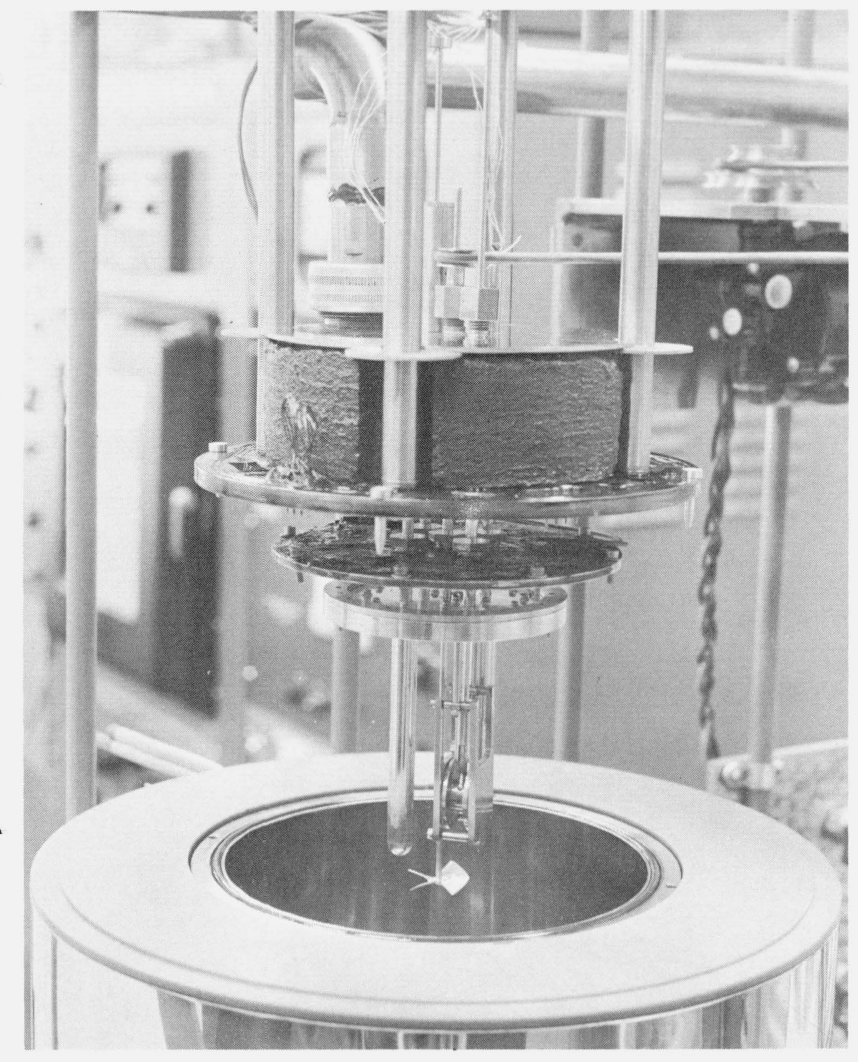

Figure 2. The open calorimeter.

The jacket well (at bottom) and above it the stirrer, the first sample holder, the wells for the heater and the thermometer. Near center, the covers for the vessel, the shield, and the jacket.

trical calibration occurs between the third and fourth rating periods.

Figures 3 and 4 are schematic diagrams of the systems for measuring the calorimeter temperature and the electrical energy, and for the temperature control of the adiabatic shield. Some of the equipment used in these measurement and control systems are shown in figure 5 , and will be described in detail later in this paper. In the first rack (foreground) are the instruments for measuring and recording temperature changes in the calorimeter vessel. The resistance of the 25- $\Omega$ platinum resistance thermometer is measured with the G-3 Mueller-type thermometer bridge (on the table) using a microvolt amplifier or a nanovoltmeter as a null detector, and the output of the null detector is recorded on the strip chart recorder near the top of the rack. Recently the platinum resistance thermometer was replaced by a quartz-oscillator thermometer which was calibrated against the $25-\Omega$ platinum resistance thermometer; the temperature changes were read directly in ${ }^{\circ} \mathrm{C}$ on the quartz thermometer.

In the second rack shown in figure 5 are the instruments for controlling the temperature of the adiabatic shield, the jacket cover, and the aluminum block above the jacket. Above the table top in this rack are the current-adjusting-type (C.A.T.) control unit and electronic null detector for controlling the temperature of the adiabatic shield. The output of the null detector (which indicates the temperature difference between the covers of the vessel and of the adiabatic shield) is recorded on the strip chart recorder. The two sets of C.A.T. units and null detectors near the top are for the control of the temperatures of the jacket cover and the aluminum block. At the top of the second rack are ammeters which indicate the current through the heaters for the shield, the jacket cover, and the aluminum block. A constant voltage power supply below the table top (not visible in the photograph) supplies the power for the three controlled heaters.

The instruments for measuring electrical energy added to the calorimeter during calibrations are shown in the third rack in figure 5 . The power is supplied by the constant voltage power supply (at top), and the time of electrical heating is determined by the electronic counter which counts cycles of the $10 \mathrm{kHz}$ standard frequency available at NBS. Recently a solid-state counter replaced the vacuum tube instrument shown here. The six-dial potentiometer and electronic null detector are used for measurements of the current and potential drop across the calorimeter heater. In the last rack are a Pirani gauge and an ionization gauge for measuring pressure in the vacuum system, switches for directing the current through the calorimeter heater or the spill coil, and saturated standard cells against which the working current in the potentiometer is balanced.

Figure 6 is a photograph showing the general setting for the calorimeter. At left is the oil diffusion pump and the copper vacuum line with pressure gauges. On the table at right is the cup of the calorimeter vessel, and at the center is the adiabatic shield. The hydraulic lift (see sec. 3.4) is shown under the calorimeter. The insulated box at the top of the rack contains junctions for thermocouples, heaters, etc.

\section{The Calorimeter in Detail}

\subsection{The Vessel and Its Appendages}

This calorimeter was designed to measure heats of reaction in aqueous $\mathrm{HF}$ solutions; therefore, all parts in contact with the solution and its vapors are of platinum-iridium alloys or polytetrafluoroethylene (PTFE, Teflon ${ }^{1}$ ). The platinum alloys containing 10 or 20 percent of iridium were used instead of pure platinum because the greater hardness made them more suitable for machining and more resistant to abrasion.

Details of the construction of the calorimeter vessel are shown in figure 7 . The lining of the cup $(P t+10 \%$ Ir ) has an inner diameter of $6.35 \mathrm{~cm}$, a wall thickness of $0.080 \mathrm{~cm}$, and an overall height of $12.1 \mathrm{~cm}$. The width of the flange at the top of the cup is $1 \mathrm{~cm}$. All visible surfaces are highly polished. On the external surface of the cup, $0.32 \mathrm{~cm}$ of pure silver was plated

${ }^{1}$ Certain commercial products and instruments are identified in this paper in order to specify adequately the experimental procedure. In no case does such identification imply recommendation or endorsement by the National Bureau of Standards, nor does it imply recommendation or endorsement by the National Bureau of Standards, nor does it imply
that the products or equipment identified are necessarily the best available for the purpose. 


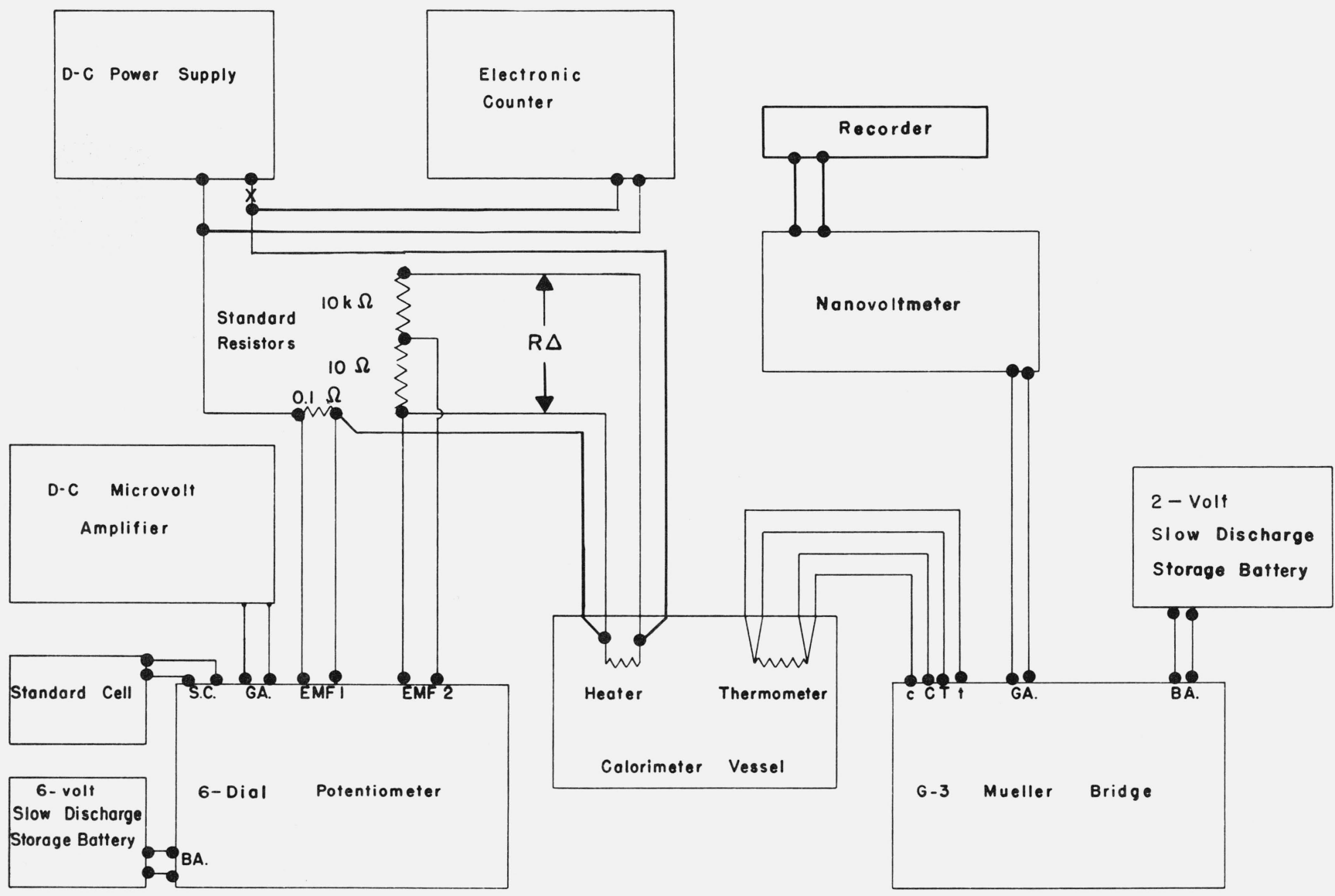

FIGURE 3. Schematic diagrams of the system for measuring the electrical energy evolved by the 97- $\Omega$ calorimeter heater during calibrations, and of the system for measuring the calorimeter temperature with the $25-\Omega$ platinum resistance thermometer. 


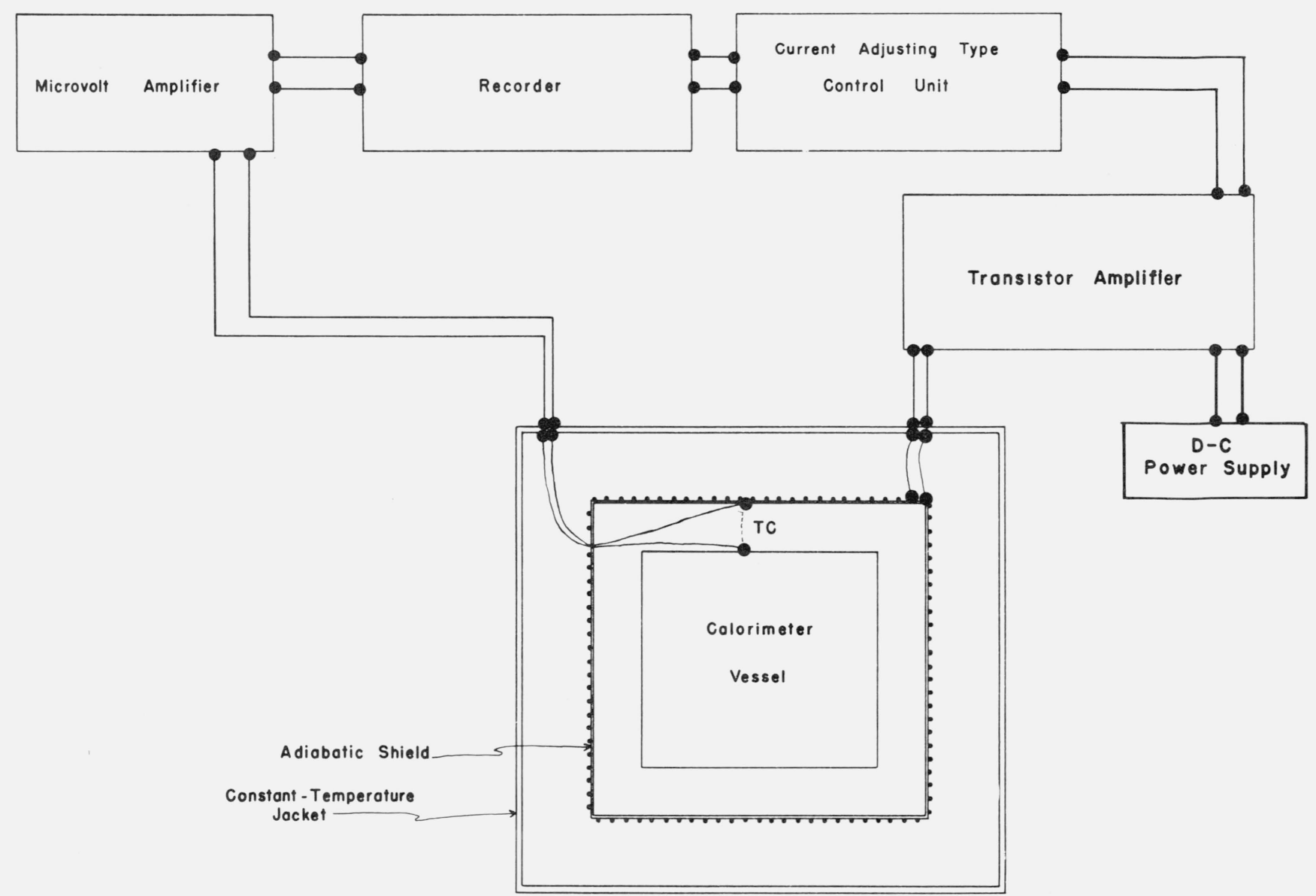

FIGURE 4. Schematic diagram of the electrical system for controlling the temperature of the adiabatic shield. 


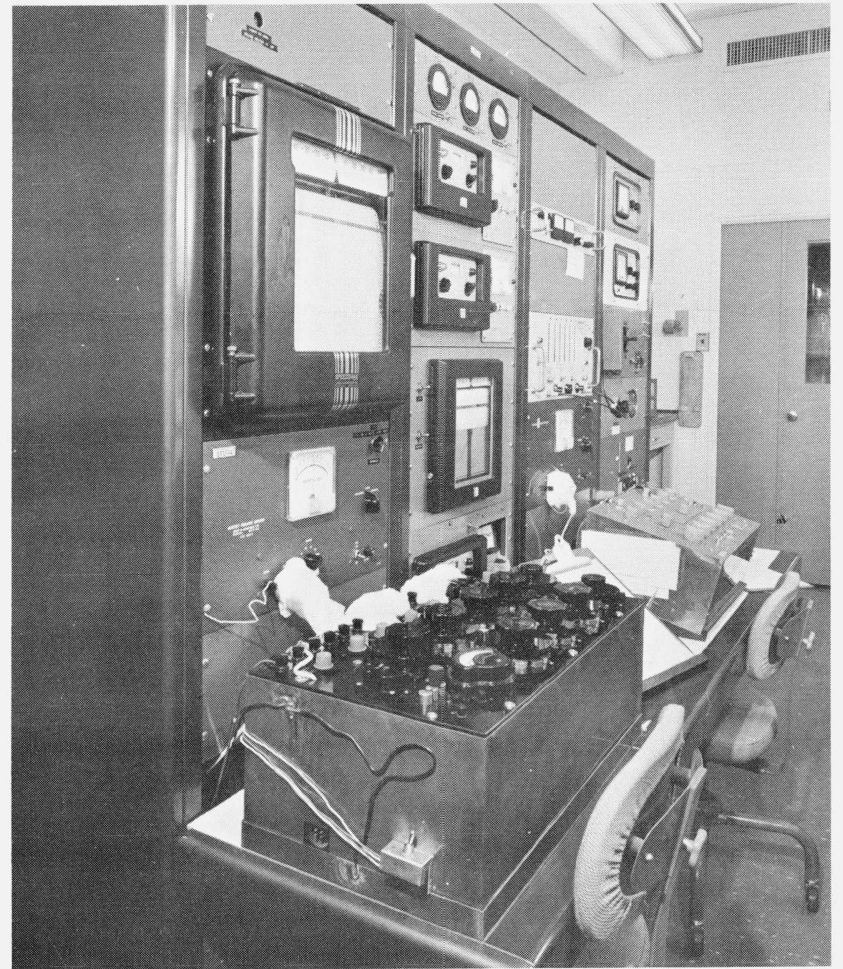

FIGURE 5. The console for the calorimeter controls and measuring equipment.

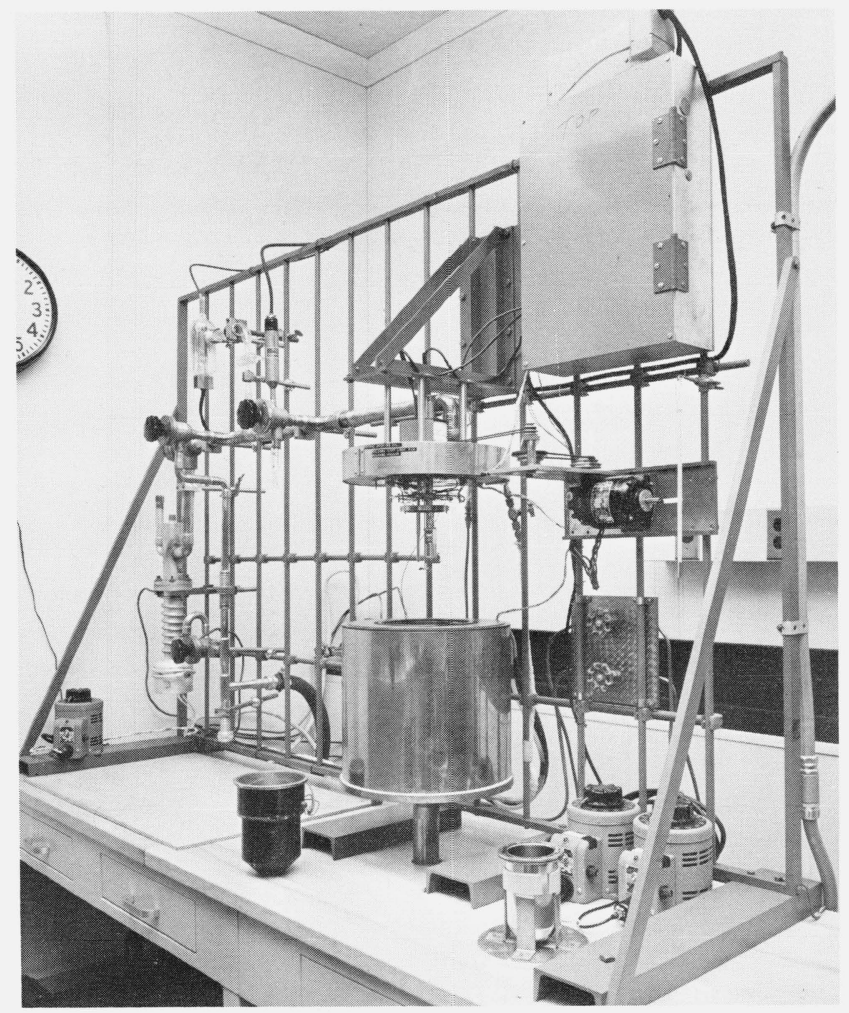

FIGURE 6. The adiabatic solution calorimeter and the vacuum system, showing the cup of the vessel on the table at right, the adiabatic shield at left, and the hydraulic lift under the case containing the jacket well and insulation.
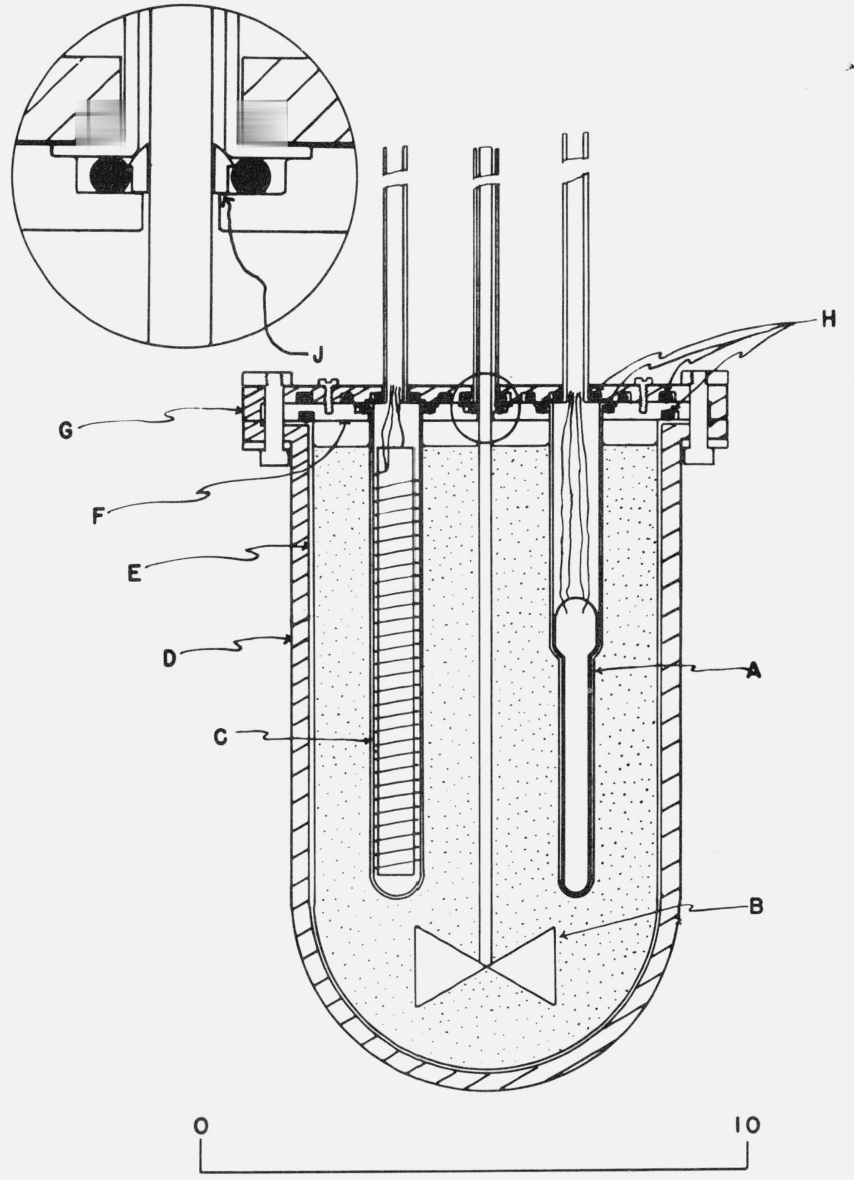

scole, centimeters

FigURE 7. A diagram showing the construction of the calorimeter vessel in detail.

(A) The well for the resistance thermometer, (B) the stirrer, (C) the well for the calibrating heater, (D) the silver vessel, (E) the platinum lining of the vessel, (F) the platinum cover, (G) the silver cover, and $(\mathrm{H})$ the rubber o-rings which seal against the vacuum surrounding the vessel. The area in the small circle is shown in detail at the upper left, and includes the PTFE bearing, (J), for the stirrer shaft.

by electrodeposition; the high thermal diffusivity of the silver rapidly distributes the heat from within the vessel and provides an essentially isothermal surface. The silver surface was plated with $\sim 0.008 \mathrm{~cm}$ of gold to prevent oxidation of the silver and to provide a highly polished surface for good reflectivity. The cup of the vessel is attached to the cover by 12 stainless steel screws which tighten on two stainless steel rings-one above and one below the flange on the vessel.

In figure 8, are the various parts of the calorimeter before assembly. At the center are shown (left to right) the stirrer, the well for the calibrating heater, the ventseal rod, the resistance thermometer and its well, and the first version of the sample holder. The cup of the vessel in its PTFE-lined holder is shown in the upper left, and to the right are the two steel rings used in attaching the cup to the cover with the steel screws shown at the left of the stirrer. Below the cup are the parts of the cover. At lower left is shown the bottom side of the gold-plated pure silver part which fits 


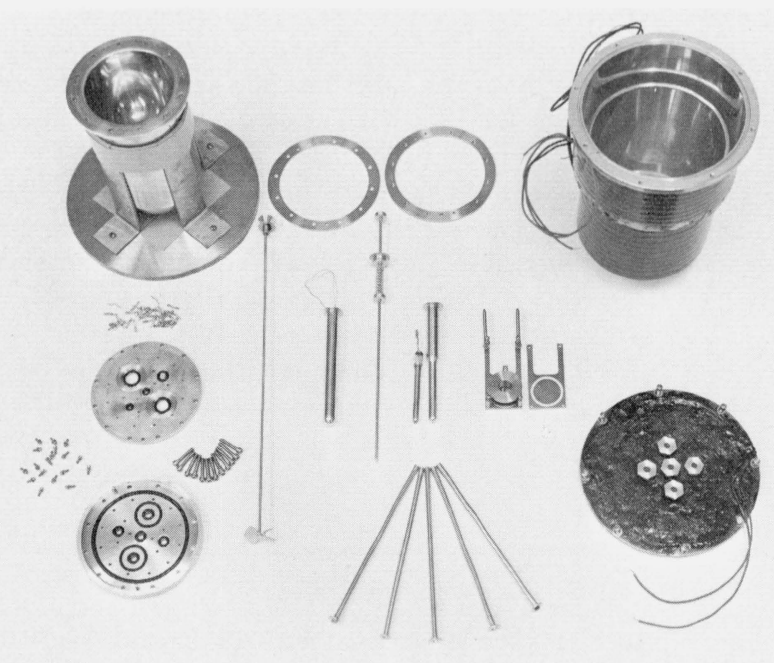

FIGURE 8. The parts of the calorimeter before assembly.

(Top to bottom) At left, the cup of the calorimeter vessel in its holder, the platinum plate of the vessel cover, and the silver plate of the vessel cover. At top center, the two steel rings used in clamping the cup and the cover of the vessel together. At center (left to right), the stirrer, the well for the calibrating heater, the first vent-seal rod, the resistance thermomete and its well, the first sample holder and cover. At lower center, the five tubes which lead up from the vessel cover. At right, the adiabatic shield and its cover.

tightly over the platinum plate $(P t+10 \%$ Ir $)$ just above it. These parts are each $0.32 \mathrm{~cm}$ in thickness. The flanged wells for the thermometer and the heater (shown near the center) seat on the large o-rings on the platinum plate; the three smaller o-rings form seals under the flanges of the platinum tubes (bottom, center) which lead up from the vessel. The two additional tubes seat in the top of the wells for the heater and the thermometer. In the assembly of the cover, the five holes in the silver part pass around the corresponding tubes seated on the platinum plate; the two parts of the cover are then positioned by means of the aligning pins and holes, located unsymmetrically near the edges of both parts. The two parts are then attached by the 18 small screws with gold-plated brass washers (at left in fig. 8) which tighten against partial taps in the platinum plate. Thus, the five small o-rings shown in the silver part form seals against the vacuum surrounding the vessel above the flanges on the five tubes. The two larger o-rings form a vacuum seal around the flanges on the heater and thermometer wells. A thick layer of Apiezon " $N$ " grease is placed on the top surface of the platinum plate before assembly to improve thermal contact between the plates and to provide an additional supply of lubricant to prevent leakage of the o-ring seals after successive high and low temperature experiments.

The cross-sectional detail of the assembled cover is shown in figure 7 . It may also be seen in figure 7 that the platinum lining of the vessel is entirely surrounded by a thick layer of silver in good thermal contact with the platinum. As a result the external surface of the calorimeter vessel may be expected to be effectively isothermal. The vacuum seal between the cup and the cover of the vessel is formed by a Buna $\mathrm{N}$ o-ring in a groove on the lower side of the platinum coverplate which seals against the flange on the cup; the outer rim of this flange is also lubricated to improve the thermal contact.

\section{a. The Stirrer Assembly}

The platinum stirrer $(\mathrm{Pt}+10 \% \mathrm{Ir})$ has a four-blade propeller which is $2.5 \mathrm{~cm}$ in diameter and is situated $10 \mathrm{~cm}$ below the cover of the vessel when assembled. The stirrer shaft passes through the platinum tube in the center of the vessel cover and is driven by a synchronous speed-reducer motor ${ }^{2}$ (1/150 hp, Bodine Electrical Type NSY-12R) through a set of pulleys and o-ring belts. Initially Buna- $\mathrm{N}$ rubber belts were used, however, an ethylene propylene rubber (Parker Seal Co., Compound E540-8) has been found to be more durable even when operating around $360 \mathrm{~K}$ for long periods.

The bearings for the stirrer shaft may be seen by reference to figures 1 and 7 . Steel ball-bearings above (not shown) and below the pulley at the top provide permanent alignment at the top of the stirrer shaft. Additional bearing surfaces not shown in figure 1 were provided later because the stirring energy did not remain constant. Variations in the stirring energy were presumed to be due to unpredictable oscillations which developed because the stirrer shaft $(0.24-\mathrm{cm}$ diameter $)$ was not supported for a length of approximately $20 \mathrm{~cm}$. Steel ball-bearings could not be used for the additional bearings because of the contact with the vapors fror 1 the calorimetric solution; therefore, two PTFE bearings were added. The first was an o-ring located under the fitting below the ball-bearing shown in figure 1 . The o-ring was not compressed by the fitting and did not form a seal around the stirrer shaft; its only function was as a bearing. A second PTFE bearing in the form of a collet was added between the two plates of the vessel cover, at a distance of $10 \mathrm{~cm}$ above the propeller (see fig. 7). This greatly reduced the oscillation problem, and the uncertainty in the stirring energy is now only 1 or 2 percent of the total. The PTFE collet was first used in November 1968, and stirring energies prior to that were less reproducible. Unfortunately, the PTFE bearings wear and after some months of use, the unpredictable oscillations may reappear. Replacement of the collet in the vessel cover is an operation which should be done infrequently because of the necessity for complete dismantling of the calorimeter; this involves breaking various soldered lead connections and removal of the control thermocouples. A satisfactory substitute for replacement of the collet is to slide a thin PTFE cylindrical sleeve $(1.25-\mathrm{cm}$ length) down the annular space between the platinum tube and the stirrer shaft until it is in contact with the collet.

Variations in the stirring speed in the calorimeter are accomplished by changes in the belt positions on a pair of pulleys; the possible combinations result in the following stirring speeds: $200,250,300,350,450$, 550,700 , and $850 \mathrm{rpm}$. Above $450 \mathrm{rpm}$, oscillations frequently occur, and these high speeds are used only

${ }^{2}$ The power is the 115-V ac supplied by the public utility in this area. Variations in the $60-\mathrm{Hz}$ frequency are small and slow enough to result in negligible error. 
when stirring reproducibility must be sacrificed to achieve more effective mixing in the solution. Below $300 \mathrm{rpm}$, there is no visible turbulence at the surface of the solution and these slow speeds are used only for reactions which require very little mixing. Of course, the reproducibility of the stirring energy at these low speeds is good.

Rating period slopes were measured near room temperature at various stirring speeds when the calorimeter contained water; the results are as follows: $120 \mu \mathrm{K} \cdot \min ^{-1}$ at $300 \mathrm{rpm}, 290 \mu \mathrm{K} \cdot \min ^{-1}$ at 450 $\mathrm{rpm}, 410 \mu \mathrm{K} \cdot \mathrm{min}^{-1}$ at $550 \mathrm{rpm}$, and $1300 \mu \mathrm{K} \cdot \mathrm{min}^{-1}$ at $850 \mathrm{rpm}$. The precision $(2 \mathrm{sdm})$ of these slope measurements ranged from 1 to 10 percent of the mean values; the precision has since been improved as the result of the addition of the PTFE bearings discussed before in this section. At higher temperatures, the rating period slopes are also affected significantly by evaporation of the calorimetric solution.

For special projects such as the measurement of the enthalpy of reaction of ketene gas in aqueous $\mathrm{NaOH}[1]^{3}$ it is necessary to seal the calorimeter by using a lubricated rubber o-ring instead of the usual PTFE o-ring in the top fitting above the jacket cover (fig. 1). In this case the uncertainty in the stirring energy and the slope is greatly increased because the rubber bearing produces less uniform friction at the seal than the PTFE does, and oscillations of the stirrer shaft are more likely to occur. Slopes as great as 700 $\mu \mathrm{K} \cdot$ min. $^{-1}$ have been observed at $450 \mathrm{rpm}$ at room temperature, although usually the observed slopes do not vary by more than 5 percent in a single experiment.

\section{b. The Vent and the Wells}

The vent was provided as (1) a safety valve in case of unexpected excessive pressure in the calorimeter, (2) an exit for gases when the system is used as a flow calorimeter, and (3) a means of assuring that the vapor space in the calorimeter is at atmospheric pressure at the beginning of an experiment. The original vent seal was a spring-loaded, $\mathrm{Pt}+10$ percent $\mathrm{Ir}$, rod (center, fig. 8) with the lower end tapered to a point which seated in a PTFE ring in the platinum cover of the vessel. The PTFE seat is shown in the platinum plate (at left center of fig. 8). Later, the spring-loading device was removed and a 100-g brass weight was attached to the top of the platinum rod which was supported by the platinum tube similar to those for the thermometer and heat leads shown in figures 1 and 7 . The vent tube is behind the stirrer in these figures on the same radius as the heater and thermometer tubes. Still later it was found that removal of the platinum rod which sealed the vent resulted in improved precision in some reactions. This insured a constant pressure system.

The wells $(\mathrm{Pt}+10 \%$ Ir) for the calibrating heater and for the thermometer (near center, fig. 8) are centered on a radius of $1.67 \mathrm{~cm}$ from the center of the ves-

${ }^{3}$ Figures in brackets indicate literature references at the end of this paper. sel cover. Both wells have a wall thickness of 0.052 $\mathrm{cm}$, are $9.2-\mathrm{cm}$ overall length, have a flange at the top which is $1.5-\mathrm{cm}$ diameter, and have an inner diameter of $0.85 \mathrm{~cm}$. On the well for the resistance thermometer, the inner diameter is reduced to $0.56 \mathrm{~cm}$ on the lower $4.4 \mathrm{~cm}$ in order to have a close fit to the capsule-type thermometer. A few drops of silicone oil in the well improved the thermal contact with the thermometer.

In the first work with the quartz-oscillator thermometer, the well for the platinum resistance thermometer was used and the quartz-oscillator probe was seated at the place where the diameter was reduced; the lower portion of the well was filled with an aluminum block to maintain good thermal conductivity.

\section{c. The Platinum Sample Holder}

The sample holder shown in figures 2 and 8 is the first design and resulted in several problems. The sample was contained in the cylinder and was sealed from the calorimetric solution by the o-rings in the two flat plates. A reaction was initiated by pulling the cylinder up (by means of the rod attached to it) into the area cut out of the end plates where the solution could circulate through the cylinder. This arrangement had the following disadvantages: (1) crystalline samples were trapped between the inner wall of the cylinder and the o-rings causing abrasion of the cylinder rims as well as difficulty in pulling the cylinder up, (2) the frictional energy was large $(>1 \mathrm{~J}$ in some cases) for pulling the cylinder up against the resistance of the o-rings, (3) the reproducibility of the opening energy was poor because of the wear and abrasion of the o-rings, and (4) the opened cylinder was near the iop of the calorimetric solutions where the stirring turbulence is relatively poor. In July 1967, the final change in design of the sample holder was completed and the improved design includes the following features: (1) the sample unit is inverted to place the open cylinder near the stirrer, (2) the o-ring grooves are in the rim of the cylinder and move with the sample across the flat end plates, and (3) a triggering device opens the sample holder allowing the cylinder to drop by gravity, thus reducing the frictional energy. The sample holder is suitable for solids and liquids of low volatility.

The sample holder was made of platinum containing 20 percent iridium for hardness, hence, resistance to wear and abrasion. The dimensions of the two flat end plates are $5.24 \mathrm{~cm}$ (height), $2.70 \mathrm{~cm}$ (width), and $0.16 \mathrm{~cm}$ (thickness). There are three interchangeable cylinders for the sample holder which have a depth of $0.95 \mathrm{~cm}$, inner diameters of $0.95 \mathrm{~cm}, 1.59 \mathrm{~cm}$, and 1.90 $\mathrm{cm}$, and contain volumes of approximately $0.7 \mathrm{~cm}^{3}, 1.9$ $\mathrm{cm}^{3}$, and $2.7 \mathrm{~cm}^{3}$, respectively.

When possible, unlubricated PTFE o-rings are used as a seal for the sample holder; however, these have sometimes been unsatisfactory for liquid samples, and lubricated o-rings had to be used. There is always some gas or vapor space with the sample in the container and as thermal expansion occurs during preheating and calibration of the calorimeter, liquid 
samples may be forced through imperfections in the PTFE seals causing prereaction, but with solid samples only small gas bubbles escape. Lubricated o-rings, PTFE or rubber, usually provide satisfactory seals for liquid samples.

The sample holder as it appears before initiating a reaction is shown in figure 9 . Holding the two end plates together at the top is the notched trigger bar. (Note that the two top nuts have been loosened and that there is a space between the shoulder of the lower cross-bars and the front end plate which permits the front end plate to pivot when the trigger is released.) To initiate a re-

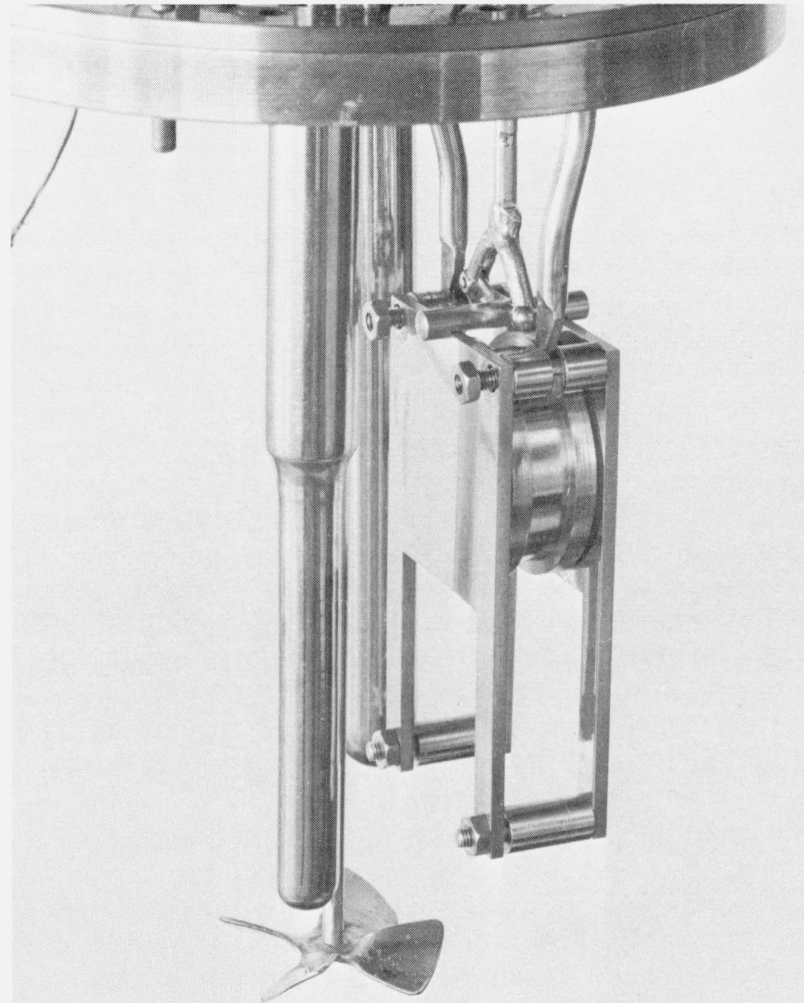

FIGURE 9. The improved platinum sample holder with trigger set as before opening.

The sample is contained in the cylinder between the two flat plates. To initiate a reaction, . rotate and release the front plate. This allows the cylinder to drop to the lower cross-bars.

action, the vertical push-rod above the trigger bar is pushed down approximately $3 \mathrm{~mm}$; the trigger bar rotates (because it is connected by a rod at its center to the pin in the end of the forked push rod) and as the notch in the trigger bar is cleared, the front end plate is released allowing the cylinder to drop to the lower cross-bars as shown in figure 10. With the cylinder in this position, the solution can circulate freely through the sample holder without danger of trapping the sample. The notch in the trigger bar can be seen more clearly in figure 10; the fork in the push rod acts as a stop when it reaches the trigger bar. The sample holder is hung on hooks on the lower ends of the two platinum rods which are screwed into the platinum cover of the vessel. When the trigger bar is raised the unit can be removed from the hooks for reassembly.

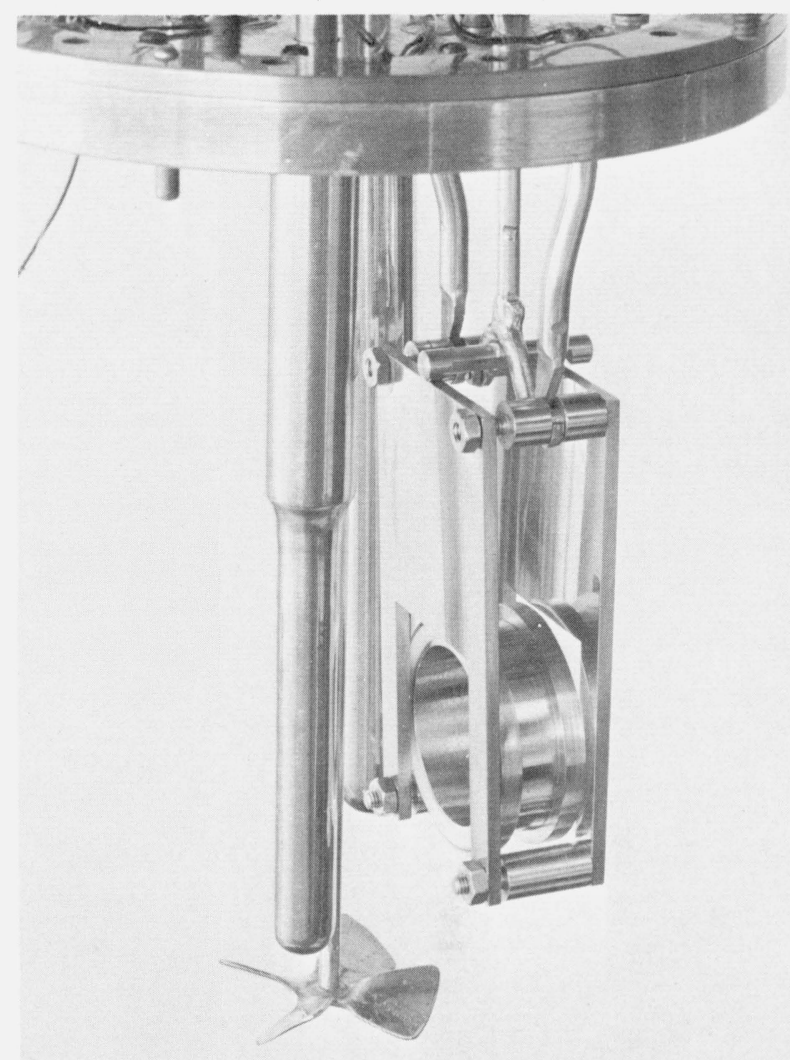

FIGURE 10. The sample holder after opening.

The notch in the trigger bar is visible as is the PTFE O-ring which before opening forms a seal with the end plate in front (A similar O-ring is on the other side of the cylinder). The sample holder is supported by the hooks suspended from the vessel cover.

In the assembly of the weighed sample holder, the fixed end plate (at back of figs. 9 and 10) with the four cross-bars attached is placed in a stainless steel clamp as shown at the top of figure 11 . The cylinder with the o-rings is placed on the fixed end plate and the two side clamps are tightened to make the lower o-ring seal. Between the lower cross-bars is a steel spacer which is removed after the assembly is completed. The unit may now be placed in a controlled atmosphere such as a dry box if necessary for filling. The sample is added to the cylinder through a funnel or dropper using care to avoid spillage on the o-ring. The second end plate is then placed on top, the four nuts are tightened, the spacer is removed, and the side clamps are released. The sample holder is now ready for weighing in the form shown at the bottom of figure 11. The mass of the empty sample holder is approximately $108 \mathrm{~g}$.

Attempts to measure the opening energy for this improved sample holder gave an average $0.00 \pm 0.02$ ( $2 \mathrm{sdm}$ ) $\mathrm{J}$ in six experiments for which the individual results were: $0.012,0.021,0.014,0.007,-0.051$, and $0.016 \mathrm{~J}$. These experiments were at $298 \mathrm{~K}$, used PTFE o-rings in the sample cylinder which was filled with the calorimetric solution (water in this case), and employed the largest, medium-sized, and smallest cylinder, in the stated order and in the reverse order. The precision of the measurements is approximately that of the stirring energy at $250 \mathrm{rpm}$, and the energy of opening 

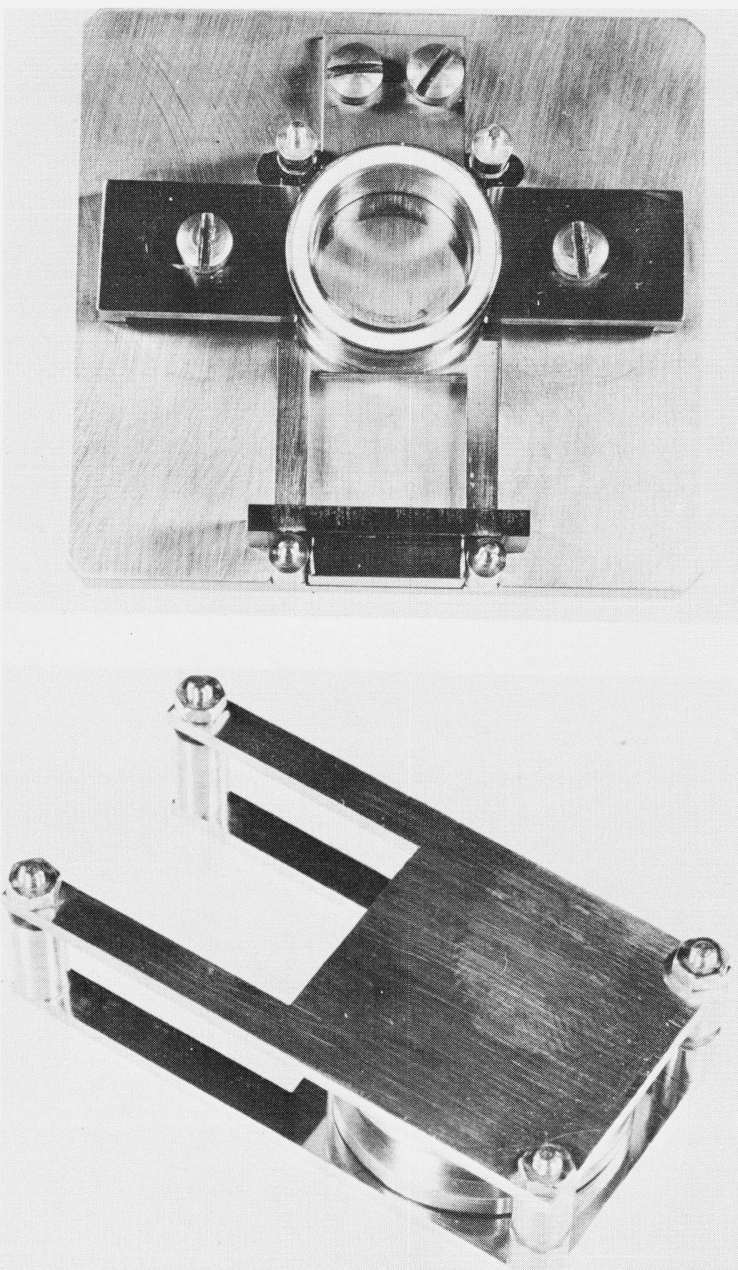

FIGURE 11. The sample holder.

At top, in the clamp ready for filling with a sample; at bottom, assembled for weighing after adding a sample.

the sample holder appears to be too small to be detectable. The temperature rises in these experiments were only $\pm 10 \mu \mathrm{K}( \pm 1 \mu \Omega)$ or less. Additional opening energies were measured as follows: -0.006 and $0.065 \mathrm{~J}$ using $9.3 \mathrm{~N} \mathrm{NaOH}$ at $298 \mathrm{~K} ; 0.031$ and 0.048 $\mathrm{J}$ using $\mathrm{H}_{2} \mathrm{O}$ at $323 \mathrm{~K} ;-0.049$ and $0.018 \mathrm{~J}$ using lubricated rubber o-rings; and $0.041,0.018$, and $0.094 \mathrm{~J}$ (the last two had only one drop of $\mathrm{H}_{2} \mathrm{O}$ in the cylinder) using conditions similar to the six experiments averaged above except that the vent tube was sealed instead of being vented to the atmosphere. The limited number of these measurements does not permit definite conclusions about the opening energies under the various conditions, however, it appears that they would not be expected to exceed $0.1 \mathrm{~J}$.

\subsection{The Adiabatic Shield}

The adiabatic shield which surrounds the calorimeter vessel is shown at the right in figure 8. It is constructed of vacuum-cast copper which is gold plated and highly polished for reflection of radiant energy.
The cover (at lower right) is 0.64-cm thick near the center and $0.32-\mathrm{cm}$ thick near the periphery. It supports the five brass fittings which hold the shield in place on the platinum tubes which rise from the vessel cover. These fittings tighten against wedge-shaped copper rings which not only provide effective support, but also provide good thermal contact between the platinum tubes and the shield cover. On the top surface of the shield cover is a manganin heater which is held in place by Glyptal insulating varnish. Eight steel screws around the edge of the cover are used to attach the base of the shield to the cover; Apiezon lubricant on the rim of the base improves thermal contact between the two metal surfaces.

The base of the shield (fig. 8, upper right) is made of continuous copper with no joints to act as thermal barriers. Its shape conforms approximately to that of the calorimeter vessel, with about $1 \mathrm{~cm}$ of space between the shield and the vessel. There are 32 annular holes $(0.32-\mathrm{cm}$ diameter) just above the central shoulder of the shield, which permit evacuation of the space between the vessel and the shield. A baffle on the shield between these annular holes and the vessel (see fig. 1) inhibits the passage of radiant energy; this is further reduced by folds of aluminum foil (not shown) in the baffle space.

The temperature of the adiabatic shield is maintained by three separate manganin heaters on the external surfaces: on the cover (115 $\Omega$ ), on the middle or baffle area above the annular holes $(135 \Omega)$, and on the lower base below the annular holes $(234 \Omega)$. The length of each of these heaters is approximately proportional to the surface area of the section covered and they are uniformly spaced on the area. The manganin heaters (\#36 AWG gauge) are held in place by Glyptal insulating varnish which was applied in several thin coats with several hours baking between each application. The Formvar-coated, copper leads (\#26 AWG gauge) were covered with glass spaghetti and attached to miniature connectors shown at the lower center of figure 12. The three shield heaters are operated by a single automatic control system, and initially the current through each heater was adjusted by means of external resistors to minimize temperature differences between the shield and the corresponding location on the calorimeter vessel as indicated by differential thermocouples. Some results of our measurements of the shield temperature profiles are discussed in section $5.2 \mathrm{a}$.

An approximate value was determined for the proportionality factor, $k$, which is the rate at which heat is transferred between the vessel and its environment per unit temperature difference. For this purpose the control point of the potentiometer in the recorder was offset by $-0.0025 \mathrm{~K}$ and by $+0.01 \mathrm{~K}$ to produce known temperature differences between the shield and the vessel. The slopes of the time-temperature curves were measured at these two offset points at various pressures and the value of $k$ was equal to the difference in slopes divided by the difference in the control point temperatures. The value of $k$ was about $0.01 \mathrm{~min}^{-1}$ at $10.1 \times 10^{4} \mathrm{~Pa}(760 \mathrm{~mm} \mathrm{Hg})$, and diminished to $0.003 \mathrm{~min}^{-1}$ at about $0.1 \mathrm{~Pa}\left(1 \times 10^{-3} \mathrm{~mm} \mathrm{Hg}\right)$ 


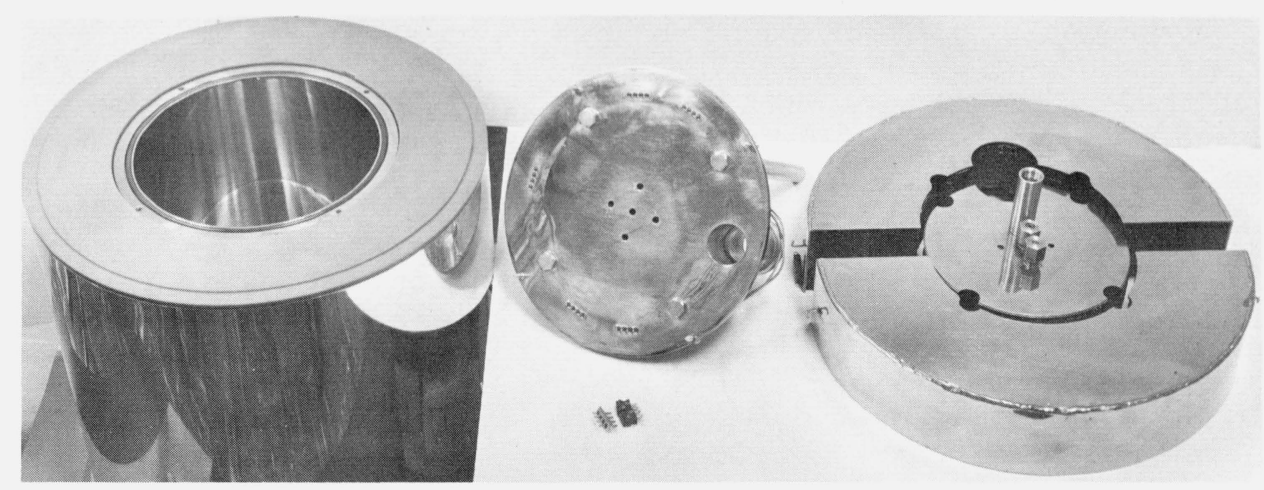

FigurE 12. The parts of the jacket.

At left, the jacket well and insulation; at center, the jacket cover; and at right, the insulation case.

where it became constant. A pressure lower than this is always maintained. The value of $k$, the heat leak constant, of $0.003 \mathrm{~min}^{-1}$ expresses the rate of temperature rise of the calorimeter in degrees $\mathrm{K}$ per degree $\mathrm{K}$ of temperature difference between the shield and calorimeter per minute. Since the energy equivalent of the calorimeter is approximately $17 \times 10^{2} \mathrm{~J} \cdot \mathrm{K}^{-1}$, this $k$ corresponds to $5.1 \mathrm{~J} \cdot \mathrm{K}^{-1} \cdot \mathrm{min}^{-1}$. During rating periods the temperature difference between the shield and calorimeter is typically controlled to within $\pm 0.0001 \mathrm{~K}$. Thus the heat leak or heat gain during rating periods is less than $0.00051 \mathrm{~J} \cdot \mathrm{min}^{-1}$ and tends to average out to zero.

During each experiment the difference between the temperatures of the covers of the shield and of the vessel is recorded. Figure 13 illustrates typical curves

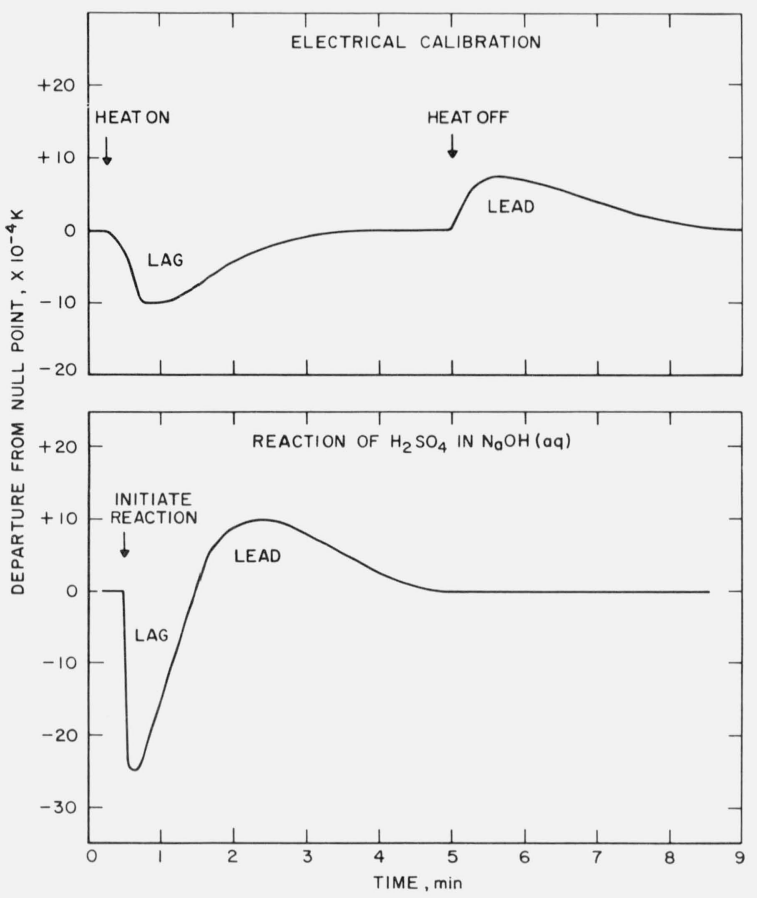

FigURE 13. Drawing showing the magnitudes of departures of the temperature of the adiabatic shield from that of the vessel.

During an electrical calibration (at top), and during a chemical reaction which resulted in a rapid $0.2-\mathrm{K}$ temperature rise in the calorimeter (at bottom). obtained during an electrical calibration and a rapid chemical reaction (Expt. No. 386, described in section $5.2 \mathrm{~b})$ which resulted in a temperature rise of $0.2 \mathrm{~K}$. When the heating is initiated in the calibration there is a "lag" when the calorimeter vessel is warmer than the shield; the maximum departure, $\sim 0.001 \mathrm{~K}$, occurs about $0.5 \mathrm{~min}$ after the heating is started, and the shield and vessel temperatures are equal about $3 \mathrm{~min}$ after initiating heating. When the electrical heating is stopped, a "lead" period results when the cover of the shield is warmer than that of the vessel. It can be seen that the areas of the lag and lead periods are essentially equal but in opposite directions which cancels heat leak errors. In the rapid chemical reaction of $\mathrm{H}_{2} \mathrm{SO}_{4}$ with $\mathrm{NaOH}(\mathrm{aq})$ the temperature difference develops quickly and calls for rapid heating of the shield which, after about $1 \mathrm{~min}$, overshoots the calorimeter temperature. A lead period of about 3 min follows when the shield cover is warmer than the vessel cover. The difference in the lag and lead areas is about $8 \times 10^{-4} \mathrm{~K} \cdot \min$. This value is multiplied by our approximate value for $k, 0.003 \mathrm{~min}^{-1}$, and the energy equivalent, $17 \times 10^{2} \mathrm{~J} \cdot \mathrm{K}^{-1}$, to obtain the correction, $0.0003 \mathrm{~J}$, which is not significant in our measurements.

\subsection{The Jacket}

Another important part of this calorimeter is the jacket which not only confines the vacuum surrounding the calorimeter vessel, but also provides a steady temperature environment for the system. The jacket is surrounded by Fiberglas duct insulation (5-cm thickness), and a coil of copper tubing on the outside which allows the circulation of cold water for measurements below room temperature (see fig. 1).

The jacket consists of two main parts, the well and the cover. The well operates at approximately constant temperature, usually 0.2 to $5 \mathrm{~K}$ below the vessel temperature to insure a demand for heat by the adiabatic shield and thus to insure positive shield temperature control. The well (fig. 12, left) has highly polished, nickel-plated, copper walls, $0.64-\mathrm{cm}$ thickness. The inner diameter is $15.5 \mathrm{~cm}$ and the depth is $21 \mathrm{~cm}$. In the rim is a groove for a rubber o-ring which forms a vacuum seal with the jacket cover and a thermal barrier between the well and the cover. 
In the jacket cover (fig. 12, center) are five holes through which pass the tubes from the vessel. Near the outer edge of the cover are four bolts which hold the stainless steel rods $(0.64-\mathrm{cm}$ diam $)$ that support the entire calorimeter assembly (see fig. 2). On the same radius are five sets of hermetic plugs (miniature side mounting connectors, shown separately below the cover in fig. 12) for electrical connections through the jacket. These plugs are used only for shield heater connections because the thermal emfs were found to be excessive for thermocouple connections. The tube at the back of the cover leads to a 1 -in dual vacuum coupling and to the vacuum system. The four pins at the rim of the cover are for alignment of the cover with the well. At right in figure 12 is a metal case containing insulation for the jacket cover.

Fittings on the jacket cover around the five platinum tubes are shown in figure 1 . Associated with each tube the first fitting above the cover compresses a rubber o-ring around the tube to form a vacuum seal; the second compresses a wedge-shaped, lubricated, copper ring around the tube to support the shield and vessel, and to provide good thermal contact between the tube and the jacket cover; and the third (center tube only) holds an o-ring which provides a bearing and/or a seal for the stirrer (there is a similar fitting for the tube containing the push-rod for the sample holder).

The five platinum tubes above the vessel are the main source of heat leak from the calorimeter. To minimize this heat leak additional heaters, automatically controlled at the shield temperature, were added to the jacket components. One heater $(61 \Omega)$ is on the top surface of the jacket cover, and a second independently controlled heater $(28 \Omega)$ is on the aluminum block which surrounds the fittings above the jacket cover. In this way, the platinum tubes and their contents are essentially brought to the shield temperature before they enter the calorimeter, and the result is effectively no heat transfer to or from the calorimeter vessel.

Initially when the calorimeter was operated at temperatures above about $300 \mathrm{~K}$, the load was too great on the automatically controlled heaters on the shield and on the jacket. Therefore, additional heaters were added to supply heat at a constant rate and their currents are adjusted by variable transformers to achieve the necessary heat input. They are located on the outer surface of the jacket well, on the connection to the vacuum line, and on the four steel support rods above the jacket cover.

\subsection{The Vacuum System and the Hydraulic Lift}

This calorimeter does not require a very high vacuum, and the system was designed for dependability and easy maintenance. The pump-down time for the system is relatively long because of the degassing of surfaces of the adiabatic shield and the various insulating materials in the system and the obstructions in the path of the molecular diffusion. About $1 \mathrm{~h}$ is required to achieve a pressure of $0.1 \mathrm{~Pa}$ $\left(1 \times 10^{-3} \mathrm{~mm} \mathrm{Hg}\right)$. Only after several days pumping can the pressure be reduced to about $1 \times 10^{-3} \mathrm{~Pa}$ $\left(5 \times 10^{-6} \mathrm{~mm} \mathrm{Hg}\right)$. Calorimetric measurements are usually started about $1.5 \mathrm{~h}$ after the pumping begins.

The vacuum system is shown in figure 6 . The heavywall, nitrometer, rubber tubing (visible behind the rack at the left of the jacket well) connects the metal vacuum line via dual vacuum couplings containing rubber o-ring seals to the mechanical pump which is an oil-sealed, rotary, mechanical type, with a rated pumping capacity of $25 \times 10^{-3} \mathrm{~m}^{3} \cdot \mathrm{min}^{-1}$. The other vacuum lines are of copper tubing with soft-soldered joints; the tubing in the lines between the oil diffusion pump (CVC Type MCF-60, capable of an ultimate pressure of $1 \times 10^{-4} \mathrm{~Pa}$ or $5 \times 10^{-7} \mathrm{~mm} \mathrm{Hg}$ at $298 \mathrm{~K}$ ) and the calorimeter is $2.86-\mathrm{cm}$ outer diameter with $0.086-\mathrm{cm}$ wall thickness, and that leading to the back-up pump is $1.90-\mathrm{cm}$ outer diameter with $0.162-\mathrm{cm}$ wall thickness. The four right-angle, high-vacuum valves in the system are the bellows type with rubber o-ring seals (CVC Type VRA). A valve of this type later replaced the glass stopcock in the line to the ionization gauge tube to reduce the possibility of breakage. The diffusion pump operates with silicone oil (Dow-Corning 704). A line by-passing the diffusion pump permits pumping the system initially with the mechanical pump before switching to include the diffusion pumping.

A hydraulic lift was made to raise the jacket well unit which weighs about $25 \mathrm{~kg}$ (see fig. 14). The unit sets on a circular, flat, brass plate attached to a brass rod, 4.76-cm diam, which is a close fit in a stainless steel cylinder, approximately $56-\mathrm{cm}$ height, $5-\mathrm{cm}$ outer diameter, and with $0.165-\mathrm{cm}$ wall thickness. The lower end of the cylinder is welded to a brass plate; near this plate, two copper tubes are welded to the steel cylinder $180 \mathrm{deg}$ apart-one of these connects to the water supply $\left(\sim 28 \times 10^{4} \mathrm{~Pa}\right.$ or $\sim 40$ psi pressure $)$ and the other to a drain, with valves in each line to control the flow of water. A guide pin (or aligning key) is located near the upper end of the cylinder and slides in a slot in the brass rod (or piston) to maintain alignment as the piston slides up and down in the cylinder; the guide pin also stops the piston from being raised too far. Two lubricated rubber o-rings in grooves near the lower end of the piston form a seal with the cylinder wall. When the well unit has been raised for a calorimetric experiment, a steel pin (safety-stop pin) is set in a hole in the piston at the top of the cylinder to prevent the unit from dropping in case of a failure of the water pressure. The level and rate of movement of this lift may be easily and precisely controlled by operation of the valves in the inlet and exit water lines (shown at the right of the well unit in fig. 6). The cross-sectional area of the piston is 17.8 $\mathrm{cm}^{2}$, and at the nominal water pressure given above, the lift is capable of raising approximately $50 \mathrm{~kg}$ which is about twice that actually required.

\subsection{The Calibrating Heater and Control Thermocouples}

Because of the important functions of the calibrating heater and the control thermocouples, there was considerable care in their design and fabrication. Some of the features included in the design of this heater 


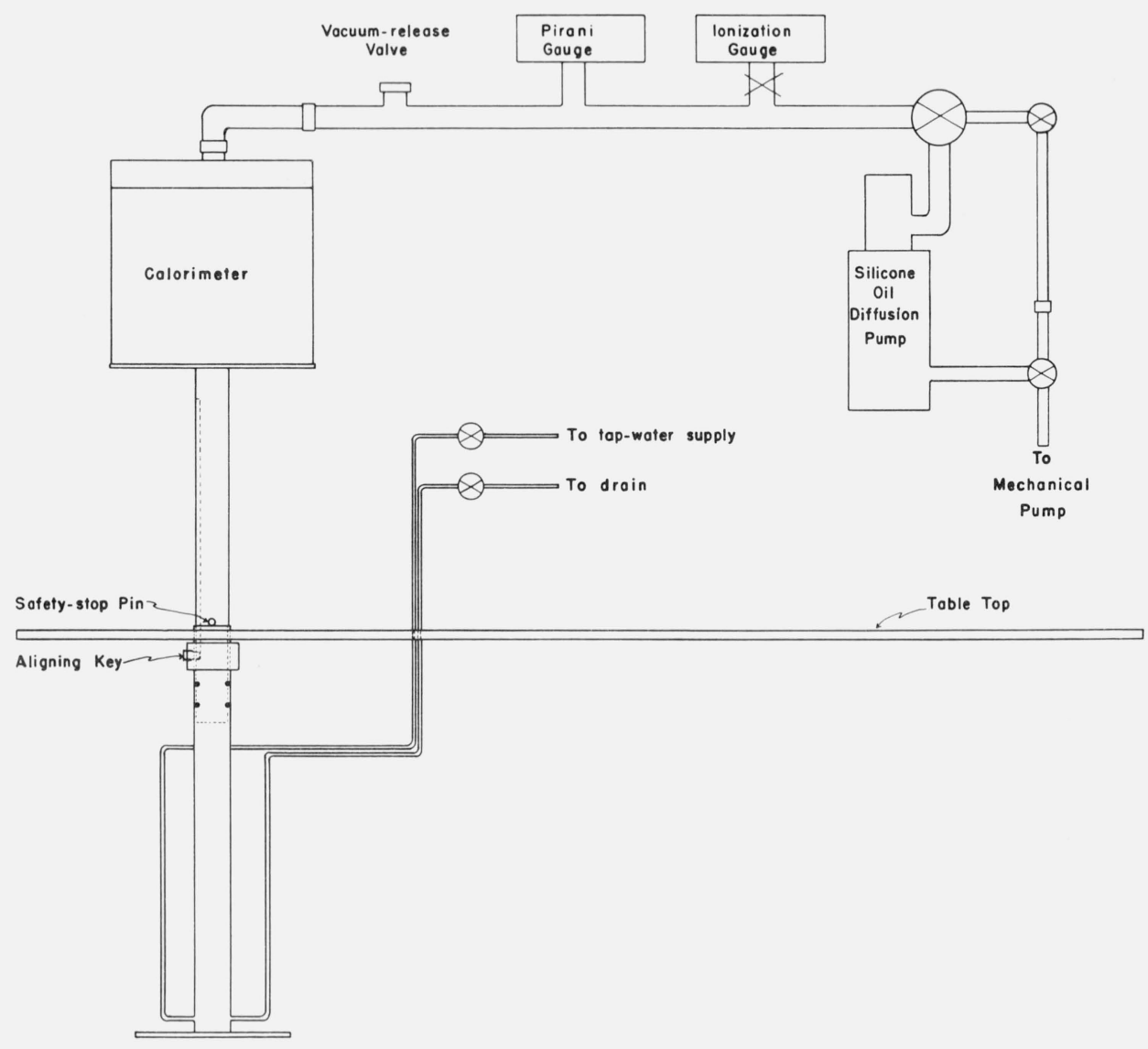

FIGURE 14. Schematic diagram of the vacuum system and the hydraulic lift for the well of the calorimeter jacket.

are: the heater wire has a high resistance per unit length to prevent unreasonably long windings, and a low temperature coefficient of resistance to avoid significant changes in the resistance over the temperature range in which it was to be used; the unit has a small heat capacity to reduce thermal lag; the conduction of heat to the well and solution is as rapid as possible compatible with the need for reliable electrical insulation; and possibly most important, the leads to the heater are arranged to minimize the transfer of heat from the calorimeter. The control thermocouples are designed to avoid heat exchange at the point of temperature detection, to achieve maximum thermal contact consistent with electrical insulation, and to provide proper temperature averaging.

The calorimeter heater (approximately $97 \Omega$, \#36 AWG gauge, enamelled, manganin wire) was wound on a stainless steel cylinder $(0.81-\mathrm{cm}$ outer diameter and $0.018-\mathrm{cm}$ wall thickness) on which two layers of Glyptal insulating varnish had been baked. The heater was wound noninductively, i.e., at the mid-point of the wire length a loop was formed and secured near the lower end of the cylinder, then the two wires coming from the loop were wound closely together around the cylinder using care to avoid crimping or overlapping the wire. When the winding was complete, the wire was secured with dental floss or silk thread and several layers of Glyptal insulating varnish were applied with baking after each layer. Copper wire (5-cm length, \#32 AWG gauge, enamelled, and cottoncovered) was soldered to each end of the manganin heater, and to each of these leads was soldered a pair of \#26 AWG gauge copper leads about $25 \mathrm{~cm}$ in length. The single copper leads were wrapped around the cylinder twice (the cylinder was indented slightly at the top to allow space for the larger wire and joints), coated with insulating varnish and baked. The unit was pushed into the close-fitting platinum well; the top of the cylinder was about $1 \mathrm{~cm}$ below the top of the well. The four Formvar-coated copper leads were looped before leaving the well, and they were held in contact with the well, $90 \mathrm{deg}$ apart, by a balsam disk. The leads were covered with PTFE spaghetti as they passed through the platinum tube and out of the calorimeter.

This heater has given years of stable performance. Its resistance changes only $0.2 \Omega$ between $298 \mathrm{~K}$ and $353 \mathrm{~K}$. The rates of heating the calorimeter range from $0.035 \mathrm{~K} \cdot \mathrm{min}^{-1}$ at $10 \mathrm{~V}$ to more than $0.5 \mathrm{~K} \cdot \mathrm{min}^{-1}$ at $40 \mathrm{~V}$.

To check the heater lead error in this "permanent" heater a series of electrical calibrations were made in which the calibrations alternated between the use of the permanent heater and of a "dummy" heater 
which was immersed directly in the calorimetric solution $\left(\mathrm{H}_{2} \mathrm{O}\right)$ so that the leads were definitely at the temperature of the solution before leaving the calorimeter. The average of 11 electrical energy equivalents measured with the permanent heater was $17,069.88$ $\pm 1.18(\mathrm{sdm}) \mathrm{J} \cdot \Omega^{-1}$ and with the dummy heater, $17,069.27 \pm 0.58(\mathrm{sdm}) \mathrm{J} \cdot \Omega^{-1}$. The difference between the two is $0.61 \mathrm{~J} \cdot \Omega^{-1}$ or 0.004 percent which is within the uncertainty of the measurements. This indicates that no significant amount of heat was transferred from the calorimeter through the heater leads. The possibility of an error due to unmeasured energy generated by current in the copper leads in the area between the shield and the junction point for the potential leads, was considered. The maximum length of the \#26 AWG gauge, copper wire involved here is about $6 \mathrm{~cm}$ which has a total resistance of about $0.008 \Omega$. Since this is only 0.008 percent of the heater resistance, the possible error from this source is assumed to be less than 0.01 percent.

The use of the six-junction thermocouple only between the covers of the adiabatic shield and the vessel is justified by the fact that lags in the rest of the system will be reproduced and compensated for in the electrical calibrations. Also, linear heat-flow theory can show that lags in the rest of the shield will cancel out in the calculation of the temperature rise. The placement of some of the thermocouples on the cover of the vessel may be seen in figure 15. Two of

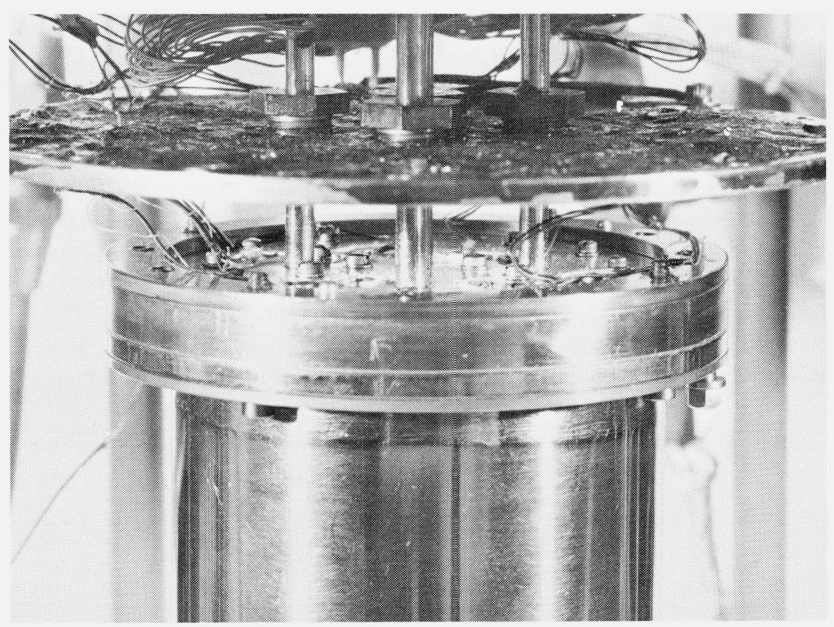

FigURE 15. The top of the calorimeter vessel showing the placement of the shield control thermocouples.

the six junctions on the vessel cover are placed between the platinum tube at the center, and the four platinum tubes which surround it; the remaining four junctions are placed between the radius of the four platinum tubes and the edge of the steel ring. The other junction of each thermocouple pair is placed on the shield cover in the location which corresponds approximately to those on the vessel cover.

The copper and constantan thermocouple wires are \#30 AWG gauge, enamelled, and asbestos covered. To form the junction, the insulation is removed on about $3 \mathrm{~mm}$ of each wire, the wires are twisted tightly together, and soft soldered with minimal amounts of solder. The junction is cut to a length of about $1.5 \mathrm{~mm}$, placed on a silver disk (about 5-mm diam and 0.08-mm thickness), and attached with a small spot of soft solder. A disk of lens tissue impregnated with epoxy cement is placed between the silver disk and the metal surface to which it is to be attached. Pressure is applied above the silver disk to extrude excess cement (which is removed) until the cement has set. The thin layer of cement insulates the thermocouples electrically without forming a significant thermal barrier. ( N,N dimethylformamide is a solvent for the cement when removal of the thermocouples is necessary.) The silver disk covers a large area relative to that of the thermocouple and because of the good thermal diffusivity of silver allows accurate surface temperatures to be measured.

This type of thermocouple is used for detecting the temperature difference between the vessel cover and the shield cover, and between the shield cover and the jacket cover. Thermocouples of the same wire but without the silver disks, using epoxy cement as insulation, were used to indicate the temperature difference between the cover and well of the jacket, and between the jacket cover and the aluminum block at controlled temperature above the jacket.

All of these thermocouples were connected through a solder-type terminal strip under the jacket cover to leads (\#28 AWG gauge, enamelled, cotton-covered, copper) which passed through a side arm in the dual vacuum coupling above the jacket cover, and then through a vacuum seal of glass and Apiezon "W" wax

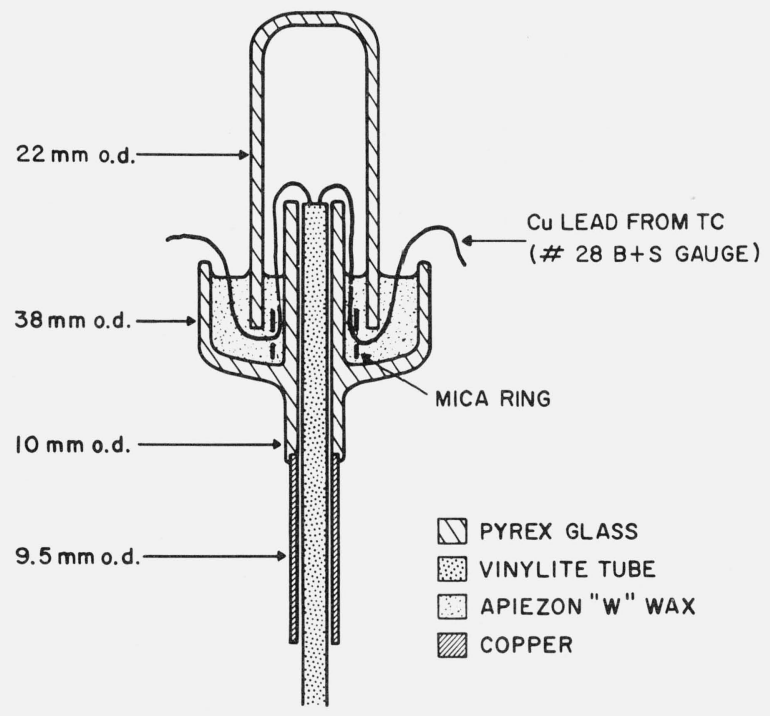

FigURE 16. A cross-sectional diagram of the vacuum seal for the thermocouple leads.

The leads pass through the plastic tubing to the top of the glass tube, then down and through the ring of mica containing holes which insure separation of the leads as they pass under the glass dome and then to the atmosphere. The dome is sealed by the Apiezon wax in the cup.

as shown in figure 16. Then they passed into the insulated terminal box where soldered connections were made to their respective circuits. 


\subsection{The Electrical Calibration and Electronic Contro Instruments}

During the 7 years that this calorimeter has been operational, many changes have been made in the electronic equipment used in the various circuits. The conversions, where possible, from vacuum tube units to transistorized and solid-state units greatly improved the dependability of the instruments and reduced the number of experiments lost because of electronic malfunctions. In some cases better instruments are known to be available now, although the additional expense has delayed replacement of the presently adequate equipment. In this section the instruments currently in use will be identified. We wish to emphasize that naming the manufacturer or a trade name is only for specific identification and does not constitute an endorsement of the product by this organization.

The $97-\Omega$ calorimeter heater is used for preheating and electrical calibrations. The pairs of current and potential leads from the calorimeter heater are connected in the insulated junction box (upper right, fig. 6) to leads from the standard resistors, and from the dc constant-voltage power supply (Sorensen Model QR40-2 A; 0-50 V; 0-2.25 A; ripple, $150 \mu \mathrm{V} \mathrm{rms;}$ voltage regulation, $\pm 0.01 \%+1 \mathrm{mV}$ ) through a toggle switch which actuates the electronic counter and directs the current either through the calorimeter heater or through a spill coil with a resistance approximately equal to that of the heater. The current through the heater is calculated from the measured potential drop across a $0.1 \Omega$ standard resistor (Rubicon Ser. No. 117443) in series with and on the low potential side of the calorimeter heater (see fig. 3). The potential drop across the heater is calculated from the measured potential drop across a $10-\Omega$ standard resistor (Rubicon Ser. No. 119222) in series with a $10-\mathrm{k} \Omega$ standard resistor (Rubicon Ser. No. 119184), and this combination is in parallel with the calorimeter heater. The potential drops are measured with a six-dial potentiometer (M-H Model 2783; the limit of error in the 0.16 $\mu \mathrm{V}$ range, $\pm 0.005 \%+0.1 \mu \mathrm{V}$ ) using a null detector ( $\mathrm{L}$ and $\mathrm{N}$ Microvolt Indicating Amplifier Cat. No. 9835-B) which had been modified to increase the sensitivity by a factor of ten ( $5 \mu \mathrm{V}$ full scale). The time of heating in electrical calibrations is measured with an accuracy of $\pm 0.001 \mathrm{~s}$ with an electronic counter (H-P Model 5216A, $3 \mathrm{~Hz}$ to $12.5 \mathrm{MHz}$ range) which counts cycles of the $10 \mathrm{kHz}$ standard frequency signals available at NBS.

The working current of the potentiometer is balanced against a saturated standard cell (Eppley Group No. 2625) which is maintained at approximately $303 \mathrm{~K}$ (constant to $\pm 0.01 \mathrm{~K}$ ) in thermostat Box No. 5. These cells are calibrated at intervals of 2 or 3 years as are the standard resistors in the electrical calibration circuit. The records of numerous calibrations over the years provide additional confidence in the values used because of the consistent trend in the calibrated values.

The three standard resistors are in a box protected from abrupt changes in ambient temperatures. The temperatures of the standard resistors are indicated to $\pm 0.02 \mathrm{~K}$ by ten-junction, copper-constantan thermocouples with ice reference junctions, and measured by a millivolt potentiometer. Switching between the thermocouples is done with a rotary selector switch (L and N Cat. No. 8248-16).

The working currents for the G-3 bridge and for the six-dial potentiometer are supplied by $2-\mathrm{V}$ and $6-\mathrm{V}$, slow-self-discharge, storage batteries (Willard DD-5-1 and DD-5-3). These batteries are recharged annually using $2.5 \mathrm{~A}$ for 2 or 3 days, and steady readings with the potentiometer cannot be made for about 2 weeks after charging.

Initially ambient temperature was found to affect the results of the potentiometer measurements. A heater was added to the guard case and controlled by a transistor-circuit temperature controller. ${ }^{4}$ This type of temperature controller has also been used with the G-3 bridge and with the standard cell box, and none of them has failed in approximately 7 years of continuous use.

The current in the automatically controlled heaters for the adiabatic shield, for the jacket cover, and for the aluminum block above the jacket is supplied by a dc, constant-voltage, power supply (Sorensen QB28-4; $18-36 \mathrm{~V} ; 0-5 \mathrm{~A}$; voltage regulation accuracy, $\pm 0.01 \%$; ripple, $<300 \mu \mathrm{V}$ rms). The thermocouple emfs for the jacket cover and for the aluminum block are sensed by the dc null detectors ( $\mathrm{L}$ and $\mathrm{N}$ Cat. No. 9834-2; maximum sensitivity, $25 \mu \mathrm{V}$ full scale or $\pm 12.5 \mu \mathrm{V})$, transmitted to the current-adjusting-type (C.A.T.) control units (Series 60, L and N Part No. 354162 ) from which the output is dependent not only upon the amount of departure from the null point, but also on the speed with which the null point is approached and the rate at which the demand is changing. Transistor-circuit power amplifiers increase the current output from the C.A.T. control units to the respective heaters. The system for the control of the adiabatic shield heaters (see fig. 4) is essentially the same except that a more sensitive null detector is used ( $\mathrm{L}$ and $\mathrm{N} \mu \mathrm{V}$ Indicating Amplifier Cat. No. 9835B, modified to increase the sensitivity by a factor of ten) and its output is recorded on a strip-chart recorder ( $\mathrm{L}$ and $\mathrm{N}$ Speedomax H, Part No. 077990) with a sensitivity in this system of $0.004 \mathrm{~K}$ per chart inch. Thus, departures of the adiabatic shield temperature from the calorimeter temperature are continuously recorded during an experiment. During rating periods, the deflections (or noise) are about $\pm 0.0001 \mathrm{~K}$; the deflections during electrical calibrations and most chemical reactions result in no significant correction to the heat of reactions. The largest departure from the calorimeter temperature in our records during the 2.5-K temperature rise of a fast chemical reaction resulted in a correction of less than 0.1 percent.

The pressure in the vacuum system is measured with a Pirani vacuum gauge (Consolidated Electrodynamics, Type GP-110) and an ionization vacuum gauge (CVC Type GIC-110B). These gauges are used

${ }^{4}$ Designed by David Brenner Electronic Instrumentation Section. 
only for approximate pressure measurements and serve to indicate malfunctions in the vacuum system.

\subsection{The Thermometers}

Until June 1972, the calorimeter temperature was measured either with a system employing a $25-\Omega$ platinum resistance thermometer or with an experimental system employing a quartz-oscillator thermometer which was used for a period of approximately 8 months. Our preliminary work with the quartzoscillator thermometer indicated that it is comparable in accuracy and precision with the platinum resistance thermometer.

The platinum resistance thermometer (see fig. 3) was connected directly through thermometer cable (exposed joints were covered with cotton to reduce thermal emfs) to a G-3 Mueller-type thermometer bridge (Rubicon Ser. No. 65471, purchased in 1952 and no longer available). The null detector was an Astrodata nanovoltmeter (Model TDA-121z) with a noise level of $<5 \mathrm{nV}$ and an accuracy of 3 percent of full scale on all ranges; the rating period measurements were made on the $10 \mu \mathrm{V}$ range. (20 $\mu \mathrm{V}$ full scale). The 3-V output of the nanovoltmeter was reduced by a divider to approximately $5 \mathrm{mV}$ for the input to the strip-chart recorder ( $\mathrm{L}$ and $\mathrm{N}$ Speedomax G, Cat. No. 60614) with a sensitivity in this system of $500 \mu \mathrm{K}$ per chart inch.

The system which employed the quartz-oscillator thermometer (H-P Model 2801A with the option providing the additional 100 -s integration period) used a modified probe-oscillator (H-P 2850D and 2830A). The response time of the probe was improved by removing the protective steel case which surrounded the probe case $(8.1-\mathrm{mm}$ diam and $6.4-\mathrm{mm}$ height, with a flange at the top which was about $1-\mathrm{mm}$ width-this is a "TO-5" transistor case). Removal of the protective case was an operation which had to be done with great care to avoid breaking the delicate leads from the quartz oscillator. The probe was placed in the same platinum well used for the resistance thermometer, and it seated just above the point where the diameter of the well was reduced; a close-fitting aluminum block was placed in the bottom of the well to reduce thermal lag and the probe was covered with silicone oil to improve thermal contact with the well.

In order to make the quartz-oscillator case fit into the well used for the resistance thermometer, it was necessary to file down the rim of the case, and in so doing the soldered seal was broken. This caused no problems until after a number of experiments at about $355 \mathrm{~K}$ when obviously erratic behavior of the quartz oscillator developed. Some droplets of oil had come in contact with the quartz crystal as a result of replacement of the gas in the case by oil during successive heating and cooling of the calorimeter. After this, the resistance thermometer system was used until a well could be made to fit a new quartz-oscillator case without reducing the diameter of its rim. More than 100 experiments were completed using the quartz-oscillator thermometer before the malfunction developed.
Digital output equipment was not available to us at the time this first probe-oscillator was used, and the temperatures were read directly in ${ }^{\circ} \mathrm{C}$ on the Nixie tube display and recorded manually. On the 100-s integration interval, the temperatures were read to $1 \times 10^{-5}{ }^{\circ} \mathrm{C}$, and the standard deviation of rating period points from the mean slope was less than $\pm 10 \mu \mathrm{K}$.

The quartz thermometer system installed in June 1972 (not used in this work) uses only the quartz probe (H-P 2850D), the probe-oscillator (H-P 2830A), and a 15-V power supply. Counting of the frequency is performed directly with a $50 \mathrm{MHz}$ counter (H-P 5326A) using the NBS standard frequency (stable to better than 1 part in $10^{11}$ ) as the time base to obtain $1-\mathrm{s}, 10-\mathrm{s}$, or 100-s integration times. This system eliminates the reference crystal and provides a more stable system. Calibration against a platinum thermometer provides the relation between frequency and temperature.

The stability of the quartz-oscillator thermometer has been found adequate for the relatively short-term requirements of solution calorimetry where the system is calibrated with each experiment, however we have not enough information now to comment on the stability over a period of weeks or months as would be required for some other types of calorimetry.

The platinum resistance thermometer system was used for periodic calibrations of the quartz-oscillator thermometer. For this purpose the resistance thermometer in a platinum well was immersed in the solution close to the well containing the quartz probe; the leads of the resistance thermometer were insulated with Pliobond cement. A few drops of silicone oil were placed in the thermometer well to improve contact between the thermometer and the well.

The NBS certified calibration of the $25-\Omega$ capsuletype platinum resistance thermometer ( $\mathrm{L}$ and $\mathrm{N}$ Ser. No. 769892) in October 1961, provided the following coefficients: $\quad \alpha=0.00392547, \quad \delta=1.4918 \quad$ (estimated value), $\beta=0$ (for $t$ above $0^{\circ} \mathrm{C}$ ), and $R_{0}=25.547 \Omega$, for the Callendar equation

$$
t=\frac{R_{t}-R_{0}}{\alpha R_{0}}+\delta\left(\frac{t}{100}-1\right) \frac{t}{100}+\beta\left(\frac{t}{100}-1\right)\left(\frac{t}{100}\right)^{3}
$$

where $t$ is the temperature in ${ }^{\circ} \mathrm{C}$. The values for $\Delta R / \Delta t$ are $0.10177 \Omega \cdot \mathrm{K}^{-1}$ at $273.15 \mathrm{~K}, 0.10104$ $\Omega \cdot \mathrm{K}^{-1}$ at $298.15 \mathrm{~K}$, and $0.09879 \Omega \cdot \mathrm{K}^{-1}$ at $373.15 \mathrm{~K}$. In January 1968, while the platinum thermometer was mounted in the calorimeter, the resistance at the ice point was measured as $R_{0}=25.5478 \Omega$. This indicated that the original calibration was unchanged within the uncertainty of the measurements.

Before 1968, our measurements were made using a thermometer current of $8.35 \mathrm{~mA}$ to achieve the desired sensitivity with the microvolt amplifier then used as a null detector. The thermometer current remained on continuously during an experiment so that the uniform heat generated by the thermometer became part of the rating period slopes. This large thermometer current caused small fluctuations in the temperature 
records which disappeared when the current was reduced to $2.75 \mathrm{~mA}$ and a more sensitive null detector was used; the fluctuations were apparently caused by a combination of stirring and thermometer heating effects. Greater stability in the thermometer current was achieved by replacing the variable resistor in the current-measuring branch of the bridge with a fixed resistor. For corrections to the $2.0-\mathrm{mA}$ current used in the thermometer calibration, we measured the $25-\Omega$ thermometer resistance at various currents and found $d R /\left(d I^{2}\right)=46.0 \mu \Omega \cdot \mathrm{mA}^{-2}$; these corrections are applied to the initial and final temperatures calculated for reactions.

\section{Procedures}

\subsection{Samples and Solutions}

The weight of samples in air is usually obtained from the difference in the weights of the sample holder empty and filled with the sample. The weight of the sample in air is multiplied by a buoyancy factor to obtain the mass or weight in vacuum; the buoyancy factor is calculated from the following equation

$$
\text { B.F. }=1+\frac{d_{\text {air }}}{d_{\text {sample }}}-\frac{d_{\text {air }}}{d_{\text {weights }}} \text {. }
$$

The weights are calibrated in terms of brass, and $d_{\text {weights }}=8.4 \mathrm{~g} \cdot \mathrm{cm}^{-3}$; and the average density of air used is $d_{\text {air }}=0.00118 \mathrm{~g} \cdot \mathrm{cm}^{-3}$. This value for the density of air applies within $\pm 0.00001 \mathrm{~g} \cdot \mathrm{cm}^{-3}$ at 22.5 $\pm 0.5{ }^{\circ} \mathrm{C}, 20$ to 50 percent relative humidity, and 745 to $760 \mathrm{~mm} \mathrm{Hg}$ pressure. The atmospheric pressure at the laboratory is normally not recorded, but a continuous record of the temperature and relative humidity is kept on a Belfort Hydrothermograph. When this calorimeter was first constructed it was located in a laboratory equipped with neither temperature nor humidity controls. In April 1966, the calorimeter was moved to the laboratory in Gaithersburg, Maryland, where the relative humidity was controlled at $30 \pm 10$ percent and the temperature, at $22.5 \pm 0.5^{\circ} \mathrm{C}$. Thus, the density of air in the laboratory is normally within the limits given above.

The calorimetric solutions are usually taken from stock solutions, initially $2000 \mathrm{~cm}^{3}$ in volume and stored in polyethylene bottles. Approximately $300 \mathrm{~cm}^{3}$ of the stock solution is transferred to a $500-\mathrm{cm}^{3}$ polyethylene bottle, the weight is adjusted to a "standard" weight for the set of experiments, the solution is poured into the cup of the calorimeter vessel which is immediately attached to the cover, the empty polyethylene bottle is weighed, and the weight in air of the solution is obtained from the difference in weights. Typically the stock solutions are prepared from distilled water in equilibrium with air, except alkali solutions for which the distilled water is boiled to remove $\mathrm{CO}_{2}$ initially. No special precautions have usually been taken to exclude $\mathrm{CO}_{2}$ from the solutions because during the calorimetric experiments the solutions are exposed to the atmosphere for several hours and the presence of small amounts of carbonate in the calorimetric solutions has little affect on the enthalpy. However, in work requiring the highest accuracy, the stock solutions have been prepared and analyzed a day or two before starting the experiments, and the solution transfers for weighing made quickly with minimal exposure to the atmosphere.

\subsection{Temperature Measurements}

When the calorimeter temperature is measured with the resistance thermometer, the sensitivity of the measurements is determined at least once in each experiment with the bridge commutator in the normal, $N$, position and readings are recorded for 20-s intervals according to the following procedure: The bridge dials are set to produce a null detector deflection of nearly zero and the first reading, $N_{1}$, is recorded; for the second reading, $\mathrm{NB}_{1}$, the thermometer current is reversed through a reversing switch; and for the third reading, $\mathrm{NF}_{1}$, the thermometer current is again switched to the first direction. Then the bridge dials are changed to produce nearly a full scale deflection on the recorder chart, and similar readings are recorded, $\mathrm{NF}_{2}, \mathrm{NB}_{2}$, and $\mathrm{NF}_{2}$. The bridge dials are then returned to the values used in the first set of readings and this procedure repeated to produce $\mathrm{NF}_{3}, \mathrm{NB}_{3}$, and $\mathrm{NF}_{3}$. The deflections for the NB readings in each set are subtracted from the corresponding average of the two NF readings, and then the average difference, $\Delta$, from the first and third sets is subtracted from the difference for the second set, or $\Delta_{D}=\Delta_{2}-1 / 2\left(\Delta_{1}+\Delta_{3}\right)$. The sensitivity of the measurements is $\Delta_{D}$ divided by the change in resistance between sets 1 and 2 .

During rating periods, a single temperature measurement is the average of nine separate readings recorded for 20-s intervals. A measurement is made as follows: three readings are recorded with the commutator in the normal, $\mathrm{N}$, position, $\mathrm{NF}_{1}, \mathrm{NB}_{1}$, and $\mathrm{NF}_{1}$, as described above; for the next three readings, $R_{2}$, $R B_{2}$, and $R F_{2}$, the commutator is in the reverse, $R$, position, and the bridge dials are adjusted to produce small deflections; for the last three readings, $\mathrm{NF}_{3}$, $\mathrm{NB}_{3}$, and $\mathrm{NF}_{3}$, the commutator is returned to the $\mathrm{N}$ position and the bridge dials are again adjusted. The current reversals correct for thermal emfs and zero drifts, and the commutator reversals correct for differences in lead resistances. Three minutes is required for a single temperature measurement and the calculated temperature corresponds to the time at the mid-point of the measurements. To calculate the temperature, the $\mathrm{B}$ current deflections are subtracted from the average of the two F current deflections in each of the three groups, and these differences are multiplied by the sensitivity (described above) to obtain the resistance to be added to the dial readings; then half the resistance in the $R$ position plus half of the average of the 2 resistances in the $\mathrm{N}$ position, or $R_{t}=1 / 2\left[R_{2}+1 / 2\left(R_{1}+R_{3}\right)\right]$ gives the thermometer resistance at the mean time of the measurement.

These temperature readings are made at 5-min intervals during rating periods and there are a mini- 
mum of three but usually five readings per rating period. Equations were formulated for our use, by Joan R. Rosenblatt (Statistical Engineering Section), which produce a least squares fit to the slope of a number of equally spaced points. These equations are used in our rating period temperature slope calculations. The slope for each pair of obsevations is calculated as the difference in resistance per unit time, $S_{1}=\left(R_{2}-R_{1}\right) / \Delta t, \quad S_{2}=\left(R_{3}-R_{2}\right) / \Delta t$, etc., and the least squares fit is obtained using the following formulae:

$$
\begin{array}{ll}
n=3, & \left(S_{1}+S_{2}\right) / 2 \\
n=4, & \left(3 S_{1}+4 S_{2}+3 S_{3}\right) / 10 \\
n=5, & \left(2 S_{1}+3 S_{2}+3 S_{3}+2 S_{4}\right) / 10 \\
n=6, & \left(5 S_{1}+8 S_{2}+9 S_{3}+8 S_{4}+5 S_{5}\right) / 35
\end{array}
$$

where $n$ is the number of temperature readings. A more general equation is: slope $=\left\{6 /\left[n t\left(n^{2}-1\right)\right]\right\}$ $\left[i(n-i) d_{i}\right]$ for the summation between the limits $i=1$ to $n-1$, where $n$ is the number of equally spaced points (or temperature measurements), $t$ is the time interval, and $d$ is the difference between successive points.

In figure 17 is a plot of a time-temperature curve for a chemical reaction or an electrical calibration

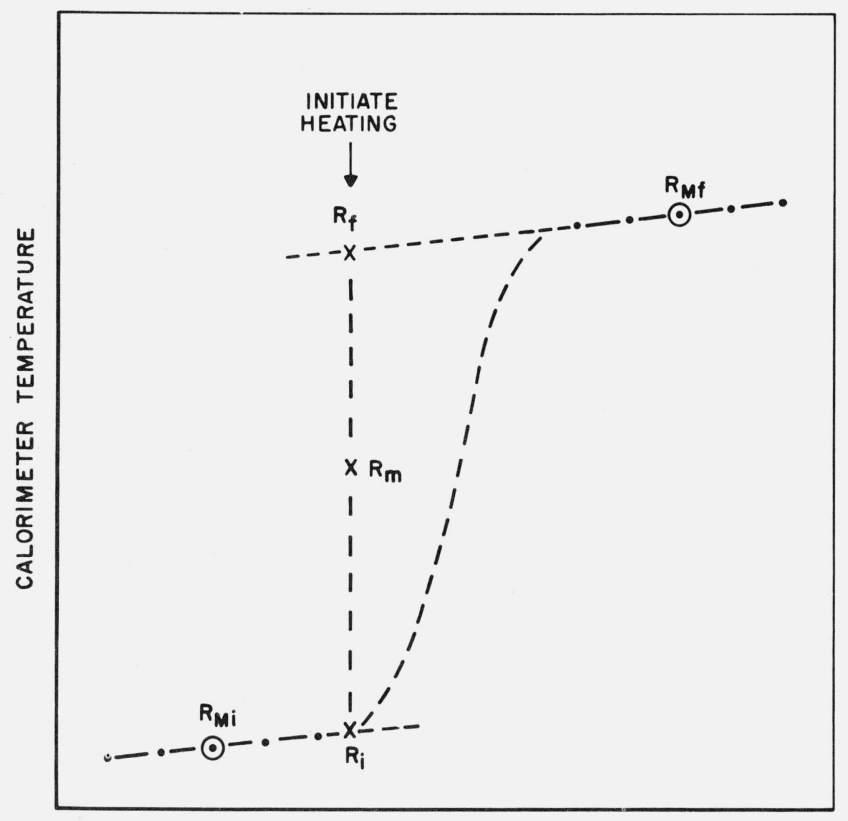

TIME

FIGURE 17. A plot showing various points used in calculating the corrected temperature rise and the mean temperature of reaction.

$R_{\mathrm{Mi}}$ and $R_{\mathrm{Mf}}$ are the mean temperatures of the rating periods, $R_{i}$ and $R_{f}$ are the initial and final temperatures of reaction, and $R_{m}$ is the mean temperature of reaction.

showing various points used in the calculation of the corrected temperature rise, $\Delta R_{c}$, in a normal experiment. Five temperatures for each rating period are calculated as described above, and the mean of these for the initial rating period is $R_{\mathrm{Mi}}$ and for the final rating period is $R_{\mathrm{Mf}}$. If $S_{i}$ and $S_{f}$ are the slopes of the initial and final rating periods, respectively, then the initial temperature of reaction, $R_{i}$, and the final temperature of reaction, $R_{f}$, are

$$
R_{i}=R_{\mathrm{Mi}}+S_{i}\left(\Delta t_{i}\right) \text { and } R_{f}=R_{\mathrm{Mf}}-S_{f}\left(\Delta t_{f}\right)
$$

where $\Delta t_{i}$ is the time interval between the mid-point of the initial rating period and the time of initiating heating (or reaction), and $\Delta t_{f}$ is the time interval between the mid-point of the final rating period and the time of initiating heating. The precise time to which the slopes are extrapolated is not important since $S_{i}$ and $S_{f}$ are nearly the same and no corrections need to be made for heat exchange with the environment. The corrected temperature rise is $\Delta R_{c}=R_{f}-R_{i}+R_{b}$ where $R_{b}$ is a small bridge dial correction; and the mean temperature of reaction is $\boldsymbol{R}_{m}=\left[\left(\boldsymbol{R}_{f}+c_{1}\right)+\right.$ $\left.\left(R_{i}+c_{2}\right)\right] / 2$ where $c_{1}$ and $c_{2}$ both include bridge dial corrections and corrections to $2 \mathrm{~mA}$ thermometer current.

During our first experiments using the quartzoscillator thermometer for the calorimeter temperature measurements, the output had not been automated and the temperatures were read directly on the Nixietube display in the thermometer chassis. Readings appeared at 100-s intervals for rating periods. This procedure was followed for the experiments to be discussed in section 5 . In this case, the temperature slopes of the rating periods were computed as the slopes of the straight lines providing least squares fits of 15 to 20 time-temperature readings.

In very slow reactions, which are frequently measured in this calorimeter, it is impossible to determine precisely the time when the reaction is complete; fortunately, this is not important because the calorimeter is adiabatic and corrections for heat transfer to the surroundings are negligible. The criteria for determining when the reaction is complete are (1) when the slope of the calorimeter time-temperature curve has not changed significantly for $1 \mathrm{~h}$, or (2) when the slope of the time-temperature curve is equal to that preceding the reaction. The first criterion is preferred because small differences in the slopes of the rating periods before and after the reaction may be the result of a change in the stirring energy because of a change in the viscosity of the solution at the higher temperature and a different composition.

\subsection{Electrical Calibrations}

The voltage across the calorimeter heater may be varied from 0 to $40 \mathrm{~V}$. The highest voltage is used only for preheating the calorimeter at the rate of about $0.55 \mathrm{~K} \cdot \mathrm{min}^{-1}$ for reactions at high temperatures. Above about $30 \mathrm{~V}$, the current and potential readings are less stable than desired, possibly because the heat transfer through the well is not adequate at the higher temperature. Therefore, electrical calibrations are usually carried out in the range of 10 to $30 \mathrm{~V}$ (heating rate, $0.03 \mathrm{~K} \cdot \mathrm{min}^{-1}$ to $0.30 \mathrm{~K} \cdot \mathrm{min}^{-1}$ ). 
In this adiabatic calorimeter it should not be necessary to match the shape of the time-temperature curves in the calibrations with those of the chemical reaction, because there are normally no corrections for heat transfer to the surroundings. However, the voltage and duration of heating in the calibrations are usually chosen so that the temperature rise is approximately equal to that caused by the chemical reaction. The time of heating is not more than 12 min nor less than 2 min, which allows sufficient time to obtain enough readings of current and potential across the heater for a good average. We have not found evidence that variations in the time or voltage selected for calibrations of a given system affect the electrical energy equivalent significantly. However, in some systems, the electrical energy equivalents do change nonlinearly with temperature and it may be necessary to obtain thermal coefficients for the calibrations in order to extrapolate to the mean temperature of reaction. In most systems the change in heat capacities with temperature is negligible and/or linear; therefore, calibrations of the initial and final systems are usually sufficient.

The following procedure is used in the electrical calibrations. Before starting the electrical heating, the temperatures of the three standard resistors are recorded, the working current of the potentiometer is balanced against the standard cell voltage, and the zero readings are made for the "current" and "potential" circuits. A toggle switch directs the current from the spill coil to the calorimeter heater, and starts the electronic counter. After $30 \mathrm{~s}$, the first reading of the current through the heater is made, and $30 \mathrm{~s}$ later the first reading of the potential drop across the heater. Alternate readings of the current and potential drop are made at 30 -s intervals until the heating is stopped by reversal of the toggle switch which simultaneously stops the counter. Readings are recorded of the time shown on the counter, and again of the temperatures of the three standard resistors, and the zero readings for the "current" and "potential" circuits. The change in the working current is observed and this completes the electrical energy measurements.

The electrical energy measured in the calibrations is calculated as follows: The thermal coefficients for the standard resistors are used to correct the value calibrated at $298.15 \mathrm{~K}$ to that at the average temperature of the resistors during the electrical calibration. An additional small resistance (usually less than 0.5 $\Omega$ ), $R_{\Delta}$ (see fig. 3 ), is the resistance of the leads included in the circuit for measuring the potential drop across the heater, to the branch points on each side of the heater; this resistance is a constant as long as the circuit remains unchanged. The averages of the voltage readings (corrected for the mean zero readings) for the current, $e_{i}$, and for the potential drop across the heater, $e_{e}$, are corrected for small changes in the potentiometer working current during the calibration and by addition of potentiometer dial corrections. The current through the heater, $I$, is equal to the difference between the current through the 0.1- $\Omega$ standard resistor and the current through the $10-\Omega$ standard resistor, or $I=\left(e_{i} / R_{0.1}\right)-\left(e_{e} / R_{10}\right)$. The voltage drop across the heater, $E$, is the product of the current through the $10-\Omega$ standard resistor and the total resistance in this branch of the circuit, or $E=\left(e_{e} / R_{10}\right) \quad\left(R_{10 \mathrm{k}}+R_{10}+R_{\Delta}\right)$. The electrical energy equivalent is $(E I t) / \Delta R_{c}$, where $t$ is the measured time of electrical heating and $\Delta R_{c}$ is the corrected temperature rise. A small correction, $0.40 \mathrm{~J} \cdot \Omega^{-1}$, is added to the energy equivalent of the initial system to correct for the heat capacity change when the sample holder is opened (the platinum push-rod is pushed down approximately $3 \mathrm{~mm}$ ).

In the normal experiment, an electrical calibration of the initial system is followed by the chemical reaction and then by an electrical calibration of the final system. When the product of the corrected temperature rise for the reaction and the energy equivalent of the initial system is divided by the amount of sample, we obtain the enthalpy of reaction referred to the "final temperature" of reaction; similarly, the product of the $\Delta R_{c}$ of reaction and the energy equivalent of the final system divided by the amount of sample gives the enthalpy of reaction referred to the "initial temperature" of reaction. The difference between these two enthalpies is a useful indicator of errors in calculations or measurements, and the mean of these two enthalpies is $\Delta H_{r}$ at the temperature of reaction which we define as the mean temperature of reaction, $R_{m}$ or $\bar{T}$ reaction.

\section{Measurements of a Standard Reaction}

An all-purpose, reliable, standard reaction for general solution calorimetry with a known enthalpy value of high accuracy and precision has not yet been established. Gunn [2] has discussed various reactions which have been used for comparison of solution calorimeters. Potassium chloride was objectionable because of the endothermic enthalpy of reaction which may introduce some unknown effects in the heat transfer in some calorimeters, and as Parker has shown [3] there is disagreement as to the best value for the reaction. The reaction of tris(hydroxymethyl)-aminomethane in aqueous $\mathrm{HCl}$ has also produced results from various calorimeters which are in poor agreement for reasons not fully explained. We decided to measure the enthalpy of reaction of aqueous $\mathrm{H}_{2} \mathrm{SO}_{4}$ in $\mathrm{NaOH}$ solutions since a sample was given to us of the same $\mathrm{H}_{2} \mathrm{SO}_{4}$ solution with which Gunn had obtained results with an experimental imprecision of less than 0.01 percent.

In this section will be given the results of our measurements with this sample in two concentrations of $\mathrm{NaOH}$ solutions which were also measured by Gunn. Our measurements began in January 1970, and were completed in April 1970.

A quartz-oscillator thermometer calibrated in terms of the $25-\Omega$ platinum resistance thermometer was used for all experiments reported in this section.

Certified NBS calibrations were made as follows: Saturated standard cell No. 2625-2293, July 1969; and standard resistors No. $117443(0.1 \Omega)$, No. 119222 
(10 $\Omega$ ), and No. 119184 (10,000 $\Omega$ ), June 1969. The records of numerous calibrations over several years for the standard cell and standard resistors provide additional confidence in the values used because of the consistent trends in the calibrated values.

Calibrations were made in this laboratory of the G-3 resistance thermometer bridge dials in January 1969, and November 1970, and of the six-dial potentiometer in January 1969.

The unit of energy is the joule $(\mathrm{J})$, and $4.1840 \mathrm{~J}=$ 1 thermochemical calorie.

\subsection{The Sample and Solutions}

The sample of $\mathrm{H}_{2} \mathrm{SO}_{4} \cdot 8 \mathrm{H}_{2} \mathrm{O}$ as received from Gunn was in a $250-\mathrm{cm}^{3}$, sealed, glass bottle labeled "18Al". A private communication from Gunn explained that this was one of three bottles into which a batch of quantitatively diluted, constant-boiling acid was divided, and that one of the other bottles was used for his measurements of these reactions. The following additional information was provided:

(1) The composition of the solution corresponds to a molecular weight of 242.204 . (The nominal composition corresponds to 242.200 [4] or 242.1968 [5]; Gunn's value was used in our calculations.)

(2) The ratio of the vapor pressure of water above the solution to the vapor pressure of pure water, $a_{w}$ (or $\left.p / p^{\circ}\right)$, is 0.5554 .

(3) The apparent molar volume, $\varphi_{v}$, is $+41.3 \mathrm{~cm}^{3}$. $\mathrm{mol}^{-1}$

(4) The density of the sample was given as 1.307 $\mathrm{g} \cdot \mathrm{cm}^{-3}$. Our buoyancy factor (see sec. 4.1 ) is 1.000763 using his density for the sample.

(5) Suggestions were given for a procedure to be followed in opening the bottle and in reclosing it to prevent contamination of the sample. (These suggestions were followed closely and carefully.)

Approximately $75 \mathrm{~cm}^{3}$ of the sample was pipeted to a $100-\mathrm{cm}^{3}$ glass bottle with an inverted, standardtapered-joint cap. This was then stored in a stainless steel glove box where the calorimetric samples were to be added to the sample holder. In the glove box were three large crystallizing dishes which contained saturated solutions of $\mathrm{Ca}\left(\mathrm{NO}_{3}\right)_{2} \cdot 4 \mathrm{H}_{2} \mathrm{O}$ to maintain a relative humidity of approximately 53 percent at the laboratory temperature, thus minimizing exchange of water with the sample.

For reaction $I$, the smallest cylinder $\left(0.7 \mathrm{~cm}^{3}\right)$ with PTFE o-rings for the sample holder was used to contain the samples which were 0.59 to $0.69 \mathrm{~g}$ of the acid. In reaction II, the middle-sized cylinder (1.9 $\mathrm{cm}^{3}$ ) was used for the larger samples of acid which ranged from about 2.0 to $2.4 \mathrm{~g}$. The calorimetric acid samples were transferred in the glove-box-hygrostat to the weighed sample holder by means of a glass dropper, and the sample holder was sealed before removal from the hygrostat for reweighing and installation in the calorimeter.

The $2000-\mathrm{cm}^{3}$ lots of $\mathrm{NaOH}$ stock solutions (from which the calorimetric solutions were taken) were prepared by dilution of 0.1 or $1.0 \mathrm{~N} \mathrm{NaOH}$ solutions with freshly boiled, distilled water which was guarded by Ascarite absorption tubes, and then stored in polyethylene bottles. The stock solutions were analyzed by titration of potassium acid phthalate using a Heath Recording $\mathrm{pH}$ Electrometer with calomel and hydrogen reference electrodes. In table 1 are given the average value of three titrations for each stock solution, and the experiment numbers in which the solution was used. The calorimetric solutions were transferred to

TABLE 1. Analysis of $\mathrm{NaOH}$ stock solutions

\begin{tabular}{c|c|l}
\hline \hline $\begin{array}{c}\text { NaOH stock } \\
\text { soln. No. }\end{array}$ & Normality & \multicolumn{1}{|c}{$\begin{array}{c}\text { Used in } \\
\text { Expt. Nos. }\end{array}$} \\
\hline & mol/1000 $\mathrm{cm}^{3}$ & \\
10 & 0.0207 & $380-382$ \\
11 & .0215 & $384-387$ \\
12 & .0785 & $413,414,420$ \\
14 & .0779 & 416 \\
15 & .0770 & 424,425 \\
16 & .0774 & 427,429 \\
\hline
\end{tabular}

a polyethylene bottle for weighing and then to the calorimeter vessel; no special precautions were taken to exclude $\mathrm{CO}_{2}$ during these transfers except to work quickly and to avoid breathing directly on the solutions.

\subsection{Experimental Results}

The adiabatic solution calorimeter described in detail in sections 3 and 4 , was used to measure the enthalpy of solution of $\mathrm{H}_{2} \mathrm{SO}_{4} \cdot 8 \mathrm{H}_{2} \mathrm{O}$ in $\sim 0.02 \mathrm{~N}$ $\mathrm{NaOH}$ (reaction I), and in $\sim 0.08 \mathrm{~N} \mathrm{NaOH}$ (reaction II). The results of seven experiments for reaction I and eight experiments for reaction II are reported here.

The sample holder (see section 3.1c) functions well with solid samples but problems of prereaction due to leakage at the o-ring seals are sometimes encountered with liquid samples as was true in these measurements; thus, a total of 34 experiments were run and only 15 yielded good values although some were lost for reasons other than prereactions. When there was a large amount of prereaction the rating period slopes were abnormally high and the heats of reaction were abnormally low. Fortunately there was a definite break between the values obtained from reactions which showed no evidence of prereaction and those involving prereaction; i.e., the former values were all $34,185 \mathrm{cal} \cdot \mathrm{mol}^{-1}$ and greater and the values rejected because of prereaction were $34,164 \mathrm{cal} \cdot \mathrm{mol}^{-1}$ or less. In spite of the problems with liquid samples this sample holder was preferred over the more conventional types, such as glass or plastic containers, because no form of heat-sealing was necessary thus avoiding possible contamination of the sample; also the opening energy for this sample holder has been measured under various conditions and is known to be small and reproducible within $\pm 0.1 \mathrm{~J}$ or less (see section 3.1c). The use of heavily lubricated o-rings in some of the experiments for reaction II may have resulted in slightly higher opening energies 
and caused poorer experimental precision than that obtained in reaction I where the o-rings were unlubricated.

Between Expt. No. 388 which completed reaction I experiments and Expt. No. 411 which began reaction II experiments, measurements (to be published later in this journal) were made of the heat of reaction of tris(hydroxymethyl)aminomethane, SRM 724, in $0.1 N$ HCl which showed that higher enthalpy values were obtained when the calorimeter was sealed (unvented) as opposed to the values obtained when the calorimeter was open to the atmosphere through the vent tube or vented to atmospheric pressure through an open-end manometer containing Marcol (mineral oil). This effect was not found in the measurements of $\mathrm{H}_{2} \mathrm{SO}_{4}$. $8 \mathrm{H}_{2} \mathrm{O}$ in $\mathrm{NaOH}(\mathrm{aq})$ : all experiments of reaction I were in the unvented calorimeter and all experiments of reaction II were vented to the atmospheric pressure through an open-end manometer containing Marcol, and no "venting" effect was found.

\section{a. Temperature Profiles for the Adiabatic Shield}

Some of the experiments for reaction I were lost in respect to enthalpy measurements, but at the same time temperature profiles of the adiabatic shield were recorded which provide some information about the magnitude and duration of departures of the temperature at various locations on the shield from that at the control point.

The permanent control thermocouples (see sec. 3.5 ) are located between the cover of the vessel and the cover of the shield. For the temperature profile measurements, temporary differential thermocouples were placed between the shield cover (controlled directly) and the center interior wall of the baffle section of the shield about $2 \mathrm{~cm}$ below the cover, and the center interior wall of the base section of the shield about $5 \mathrm{~cm}$ below the upper end of the baffle (see sec.
3.2). A summary of these temperature profile observations for the shield is given in table 2.

These temperature profiles were recorded during electrical calibrations of the initial (A) or final (B) systems with heating for $4.5 \mathrm{~min}$ at $19 \mathrm{~V}$ across the calorimeter heater (temperature rise $=0.57 \mathrm{~K}$ ), or during the $\mathrm{H}_{2} \mathrm{SO}_{4} \cdot 8 \mathrm{H}_{2} \mathrm{O}$ reaction in $0.02 \mathrm{~N} \mathrm{NaOH}$ (temperature rise $=0.2 \mathrm{~K}$ ). This reaction produces an almost instantaneous temperature rise in the calorimetric solution in contrast to the relatively slow dissemination of heat from the electrical heating through the solution. However, in both cases, the heat must be transmitted from the walls of the vessel and the wells to the cover where the control thermocouples are located. This lag tends to smooth the temperature rise and prevent initial shock to the shield controls which can result in an excessive overshoot of the control temperature.

The shapes of the temperature profile curves are similar to those shown for the control thermocouples in figure 13. Initially, there is a period of about $1 \mathrm{~min}$ when the shield temperature lags behind that of the vessel (this temperature difference was never more than $0.004 \mathrm{~K}$ ). As the shield is heated there is an overshoot of the calorimeter temperature to a maximum deflection from the null point and then a period of gradual return to the null point. In table 2 it is shown that for the chemical reactions the lead maximum or the maximum departure from the null point, $<0.008 \mathrm{~K}$, occurred about $1.5 \mathrm{~min}$ after initiating the reaction and the total time of departure from the control point was $7 \mathrm{~min}$ or less; for the electrical calibrations the maximum departure occurred at 4 to 5 min after starting the electrical heating and the total time of departure from the null point was $10 \mathrm{~min}$ or less. In the last four observations given in table 2 , the control point was offset by a few thousandths $K$ and no significant effect was apparent on the profiles. The offset was

TABLE 2. Summary of temperature profile measurements for adiabatic shield during electrical heating for 4.5 min at $19 \mathrm{~V}$, and during $\mathrm{H}_{2} \mathrm{SO}_{4}$ reactions with $\mathrm{NaOH}(0.2 \mathrm{~K}$ temperature rise $)$

\begin{tabular}{|c|c|c|c|c|c|c|c|c|}
\hline \multirow{2}{*}{$\begin{array}{c}\text { Expt. } \\
\text { No. }\end{array}$} & \multirow{2}{*}{$\begin{array}{l}\text { Calibration or } \\
\text { reaction }\end{array}$} & \multirow{2}{*}{$\begin{array}{c}\text { Thermocouple } \\
\text { locations }\end{array}$} & \multicolumn{3}{|c|}{$\begin{array}{l}\text { Length of time for } \\
\text { departures from null point } \\
\text { after initiating heating }\end{array}$} & \multirow{2}{*}{$\begin{array}{l}\text { Null point } \\
\text { offset }\end{array}$} & \multicolumn{2}{|c|}{$\begin{array}{l}\text { Maximum deflection } \\
\text { from null point* }\end{array}$} \\
\hline & & & Lag & $\begin{array}{l}\text { Lead } \\
\text { Max. }\end{array}$ & Total & & $\mathrm{Lag}$ & Lead \\
\hline 374 & $\begin{array}{l}\text { Calib. A } \\
\mathrm{H}_{2} \mathrm{SO}_{4} \mathrm{I}-1 \\
\text { Calib. B. }\end{array}$ & $\begin{array}{l}\text { Cover vs. Base } \\
\text { do } \\
\text { do }\end{array}$ & $\frac{\min }{\overline{0.5}}$ & $\begin{array}{r}\min \\
4.0 \\
1.5 \\
4.5\end{array}$ & $\begin{array}{r}\min \\
10.0 \\
5.0 \\
8.5\end{array}$ & $\begin{array}{c}K \\
0.000 \\
.000 \\
.000\end{array}$ & $\frac{K}{-0.0023}$ & $\begin{array}{c}K \\
0.0092 \\
.0075 \\
.0088\end{array}$ \\
\hline 375 & $\begin{array}{l}\text { Calib. A } \\
\mathrm{H}_{2} \mathrm{SO}_{4} \mathrm{I}-2 \\
\text { Calib. B }\end{array}$ & $\begin{array}{l}\text { Cover vs. Baffle } \\
\text { do } \\
\text { do }\end{array}$ & $\begin{array}{l}\overline{0.5} \\
0.5\end{array}$ & $\begin{array}{l}4.5 \\
1.5 \\
5.0\end{array}$ & $\begin{array}{r}8.0 \\
7.0 \\
10.0\end{array}$ & $\begin{array}{l}.000 \\
.000 \\
.000\end{array}$ & $\begin{array}{r}-\overline{0028} \\
-.0010\end{array}$ & $\begin{array}{l}.0067 \\
.0059 \\
.0070\end{array}$ \\
\hline 376 & $\begin{array}{l}\text { Calib. A } \\
\mathrm{H}_{2} \mathrm{SO}_{4} \mathrm{I}-3 \\
\text { Calib. B }\end{array}$ & $\begin{array}{l}\text { do } \\
\text { do } \\
\text { do }\end{array}$ & $\begin{array}{l}1.5 \\
0.8 \\
1.5\end{array}$ & $\begin{array}{l}5.0 \\
1.5 \\
5.0\end{array}$ & $\begin{array}{l}9.0 \\
5.0 \\
9.0\end{array}$ & $\begin{array}{r}.000 \\
.000 \\
-0.005\end{array}$ & $\begin{array}{l}-.0015 \\
-.0040 \\
-.0013\end{array}$ & $\begin{array}{l}.0040 \\
.0028 \\
.0042\end{array}$ \\
\hline 388 & $\begin{array}{l}\text { Calib. A } \\
\mathrm{H}_{2} \mathrm{SO}_{4} \mathrm{I}-15 \\
\text { Calib. B }\end{array}$ & $\begin{array}{l}\text { Cover vs. Base } \\
\text { do } \\
\text { Cover vs. Baffle }\end{array}$ & $\begin{array}{l}1.0 \\
0.5 \\
1.5\end{array}$ & $\begin{array}{l}5.0 \\
1.5 \\
5.0\end{array}$ & $\begin{array}{r}10.0 \\
5.0 \\
10.0\end{array}$ & $\begin{array}{r}+0.008 \\
.006 \\
.003\end{array}$ & $\begin{array}{l}-.0008 \\
-.0020 \\
-.0012\end{array}$ & $\begin{array}{l}.0090 \\
.0063 \\
.0043\end{array}$ \\
\hline
\end{tabular}

* A negative deflection indicates that the shield is at a lower temperature than the calorimeter cover. 
accomplished by addition of a small known emf which opposed or added to that of the thermocouples and resulted in a control point which was less than or greater than zero.

It should be remembered that these temperature differences occur at points on the shield which are separated from the vessel by an evacuated space. At the covers of the vessel and the shield, where heat could be transferred by conduction through the five tubes, the temperature difference rarely exceeds $0.001 \mathrm{~K}$. Even during the most rapid electrical heating, the heat leak corrections are less than $0.001 \mathrm{~J}$ (see sec. 3.2). Also, as pointed out earlier, linear heat-flow theory can show that lags in the rest of the system cancel out in the calculation of the temperature rise.

\section{b. Enthalpy of Reaction of $\mathrm{H}_{2} \mathrm{SO}_{4} \cdot 8 \mathrm{H}_{2} \mathrm{O}$ with excess $\mathrm{NaOH}$ (aq)}

The enthalpies of reaction of the $\mathrm{H}_{2} \mathrm{SO}_{4} \cdot 8 \mathrm{H}_{2} \mathrm{O}$ in $\sim 0.02 N \mathrm{NaOH}$ (reaction I) and in $\sim 0.08 \mathrm{~N} \mathrm{NaOH}$ (reaction II) were measured and the experimental data are given in table 3 . The Expt. No. is a serial number for experiments in this calorimeter. The mass of the $\mathrm{H}_{2} \mathrm{SO}_{4}$ sample, $\mathrm{S}$, and of the calorimetric solution, $\mathrm{NaOH}$, are in columns 2 and 3 ; the concentrations of the $\mathrm{NaOH}$ solutions were given in table 1 . The calculation of the electrical energy equivalents is discussed in section 4.3 , and the corrected temperature rise, $\Delta T c$, in section 4.2 . The product of the mean electrical energy equivalent and $\Delta T c$ is divided by the sample weight to obtain the enthalpy of reaction, $\Delta H_{r}(T)$, which is equal to the enthalpy of reaction at the mean temperature of reaction, $\bar{T}$ reaction. For the correction to $298.15 \mathrm{~K}$, the value, $\Delta C p=0.28 \mathrm{~J} \cdot \mathrm{g}^{-1} \cdot \mathrm{K}^{-1}$ (16 $\mathrm{cal} \cdot \mathrm{mol}^{-1} \cdot \mathrm{K}^{-1}$ ) [2] was used. The variations in stirring rates as shown in the table, had no significant effect on the enthalpy of reaction.

In all of the experiments for reaction I unlubricated PTFE o-rings were used for the sample holder. In reaction II a larger cylinder was used for the sample holder and prereaction occurred because of failure of the o-ring seals. Consequently, in the first three experiments for reaction II unlubricated PTFE o-rings were used, in the next three, lubricated PTFE o-rings, and in the last two, lubricated rubber o-rings. The average enthalpy for the first three experiments is smaller than that for the last five experiments, and it is possible that use of the lubricant increased the opening energy in some cases. The sample-holder opening energy using unlubricated PTFE o-rings was measured as $0.00 \pm 0.02 \mathrm{~J}$, but with lubricated o-rings less is known about the opening energy. The total heat involved in these experiments was about $1300 \mathrm{~J}$, and an error of 0.010 percent $\left(3.4 \mathrm{cal} \cdot \mathrm{mol}^{-1}\right)$ would result from an opening energy of $0.13 \mathrm{~J}$.

The average enthalpy value measured in the seven experiments for reaction I corresponds to the following equation

$$
\begin{aligned}
\mathrm{H}_{2} \mathrm{SO}_{4} \cdot 8 \mathrm{H}_{2} \mathrm{O}+2.36\left(\mathrm{NaOH} \cdot 2620 \mathrm{H}_{2} \mathrm{O}\right) \\
=\left(\mathrm{Na}_{2} \mathrm{SO}_{4} \cdot 0.36 \mathrm{NaOH} \cdot 6193 \mathrm{H}_{2} \mathrm{O}\right)_{\text {soln }}
\end{aligned}
$$

$\Delta H_{r}(298.15 \mathrm{~K})=-590.692 \pm 0.101 \mathrm{~J} \cdot \mathrm{g}^{-1}$

$$
=-34,194.1 \pm 5.9 \mathrm{cal} \cdot \mathrm{mol}^{-1}
$$

and in the eight experiments for reaction II,

$$
\begin{array}{r}
\mathrm{H}_{2} \mathrm{SO}_{4} \cdot 8 \mathrm{H}_{2} \mathrm{O}+2.6\left(\mathrm{NaOH} \cdot 714 \mathrm{H}_{2} \mathrm{O}\right) \\
=\left(\mathrm{Na}_{2} \mathrm{SO}_{4} \cdot 0.6 \mathrm{NaOH} \cdot 1866 \mathrm{H}_{2} \mathrm{O}\right)_{\text {soln }} \\
\begin{aligned}
\Delta H_{r}(298.15 \mathrm{~K}) & =-590.828 \pm 0.193 \mathrm{~J} \cdot \mathrm{g}^{-1} \\
& =-34,203.4 \pm 11.1 \mathrm{cal} \cdot \mathrm{mol}^{-1}
\end{aligned}
\end{array}
$$

The precision is twice the standard deviation of the mean of the experimental values. These equations are in excellent agreement with those published by Gunn [6]; in his measurements, the $\mathrm{NaOH}$ dilutions were 2580 and $716 \mathrm{H}_{2} \mathrm{O}$, and for both reactions the excess $\mathrm{NaOH}$ was $0.5 \mathrm{~mol}$; the enthalpy values for the mean of eight experiments for reaction I, 34,195.9 \pm 2.4 $(2 \mathrm{sdm}) \mathrm{cal} \cdot \mathrm{mol}^{-1}$, and for the mean of seven experiments for reaction II, $34.200 .0 \pm 0.9(2 \mathrm{sdm}) \mathrm{cal}^{\prime} \cdot \mathrm{mol}^{-1}$, agree with ours within 0.01 percent or better. The experimental precision of our measurements is limited by the uncertainty in the stirring energy. Gunn's calorimeter is especially well-designed for measuring heats of fast, easily mixed reactions such as these because the rocking motion of the bomb produces very small and reproducible stirring energy.

The agreement between these two sets of measurements is quite remarkable considering the great differences in the calorimeters. Gunn's is a constantvolume, rocking, isoperibol calorimeter, and ours is a constant-pressure, stirred, adiabatic calorimeter.

The enthalpy of this reaction is not very sensitive to the alkali concentration near $0.05 \mathrm{~N} \mathrm{NaOH}$ as long as a significant excess exists, however, care must be taken to maintain the desired composition of the acid. We believe that this $\mathrm{H}_{2} \mathrm{SO}_{4}$ neutralization reaction is a good standard reaction for solution calorimetry where highest accuracy is desired.

\section{Other Measurements}

The range of capabilities of this adiabatic solution calorimeter can be demonstrated by some of the other enthalpies of reactions which have been measured in it. For example, the work leading to the certification of two NBS Standard Reference Materials for solution calorimetry, $\alpha$-quartz [7] and [8], and tris(hydroxymethyl)aminomethane [9], was done in this calorimeter. The enthalpy of solution of quartz in 24.4 percent HF was measured from 298 to $358 \mathrm{~K}$, and at $353 \mathrm{~K}$ in 18 to 30 percent $\mathrm{HF}$, with an experimental imprecision of $\pm 0.4 \mathrm{~J} \cdot \mathrm{g}^{-1}( \pm 0.017 \%)$ at the 95 percent confidence level. At $353 \mathrm{~K}$, solution of the sample required approximately $2 \mathrm{~h}$. In contrast, the rapid reactions at $298 \mathrm{~K}$ of tris(hydroxymethyl)aminomethane in $0.1 \mathrm{~N} \mathrm{HCl}$ and in $0.05 \mathrm{~N} \mathrm{NaOH}$ resulted in experimental imprecision $(2 \mathrm{sdm})$ of \pm 0.017 and 0.08 percent, respectively. The relatively poor precision in the latter 
TABLE 3. Data for the reactions of $\mathrm{H}_{2} \mathrm{SO}_{4} \cdot 8 \mathrm{H}_{2} \mathrm{O}$ in $0.02 \mathrm{~N} \mathrm{NaOH}$ (Reaction I) and in $0.08 \mathrm{~N} \mathrm{NaOH}$ (Reaction II)

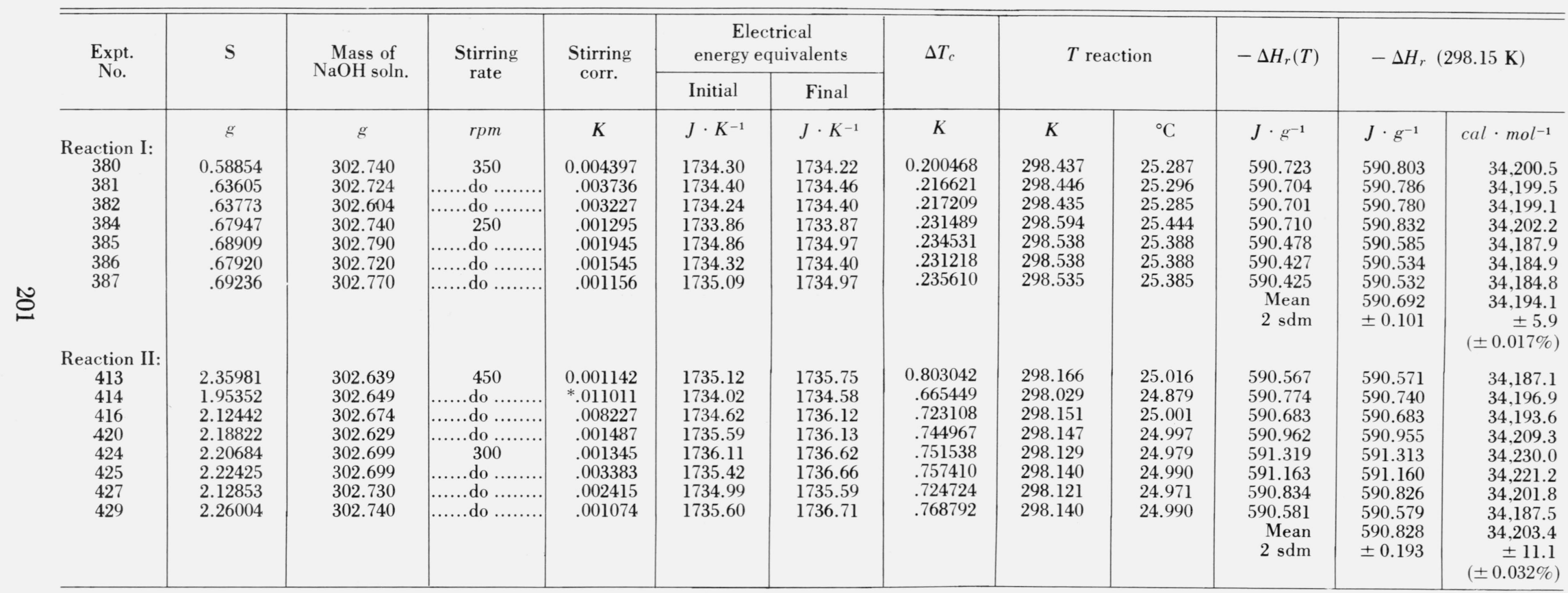

*Before this experiment, a PTFE sleeve was installed between the stirrer shaft and the platinum tube. This increased the stirring energy until it became worn. 
reaction was due to in part to the high sensitivity of the enthalpy to the $\mathrm{NaOH}$ concentration. This was an endothermic reaction in which electrical energy was added during the reaction in order to maintain a temperature rise in the calorimeter. Details of the work involved in these two certifications are to be published in this Journal.

In the reaction of ketene gas with aqueous sodium hydroxide [1], the calorimeter was modified to function as a flow calorimeter by using the vent tube for the exit gas, and by removing the sample holder and push-rod and replacing them with a metal tube for introducing the ketene gas into the calorimeter. Here the experimental imprecision $(2 \mathrm{sdm})$ was only \pm 0.47 percent, but was adequate for this work.

The results will be given [10] for our measurements of the enthalpy of solution of $\mathrm{BeO}(\mathrm{c})$ in aqueous $\mathrm{HF}$ and in aqueous $\mathrm{HCl}$; the experimental imprecisions $(2 \mathrm{sdm})$ were \pm 0.09 and \pm 0.4 percent, respectively. The latter measurements were especially interesting calorimetrically because the stirred reaction required approximately $20 \mathrm{~h}$ for completion; this caused excessive uncertainties because of the large total stirring energy. This uncertainty was reduced by turning the stirrer off during most of the reaction period and the reaction proceeded unstirred until it was near completion.

\section{Conclusions}

It has been shown that the optimum experimental imprecision $(2 \mathrm{sdm})$ achieved with this adiabatic solution calorimeter is about \pm 0.02 percent, and the $\mathrm{H}_{2} \mathrm{SO}_{4}$ measurements indicate that the accuracy of the calorimetry is probably of the order of 0.05 percent or less where $200 \mathrm{~J}$ or more of energy is evolved.

The advantage of the adiabatic calorimeter over isoperibol calorimeters has been proven in its ability to measure heats of slow reactions (of $20 \mathrm{~h}$ or more in duration) with relatively high precision. The versatility of this calorimeter has been demonstrated in the ability to make high precision measurements of slow or rapid reactions, exothermic or endothermic, with temperature rises from 0.2 to $2 \mathrm{~K}$ or more, over a temperature range of 293 to $363 \mathrm{~K}$, in highly corrosive solutions such as strong acids and bases, and even in a gas flow system.

The calorimeter is limited to reactions occurring at or near atmospheric pressure and to solutions which do not react with the platinum alloys. The limit of energy detection is approximately $0.05 \mathrm{~J}$, and the experimental precision is usually limited by the uncertainty in the stirring energy which is about 1 to 5 percent of the total stirring energy.

Adiabatic solution calorimeters are especially needed in fields, such as biology, geology, and mineralogy, where there is an interest in the properties of materials which react slowly in solutions.

The authors wish to express their gratitude for financial support for the construction of this calorim- eter by the U.S. Atomic Energy Commission. We also thank S. R. Gunn, Lawrence Radiation Laboratory, for giving us samples of $\mathrm{H}_{2} \mathrm{SO}_{4} \cdot 8 \mathrm{H}_{2} \mathrm{O}$.

\section{Prefixes, Symbols, and Abbreviations}

Prefixes:

\begin{tabular}{|c|c|}
\hline M & $\operatorname{mega}\left(10^{6}\right)$ \\
\hline k & kilo, $\left(10^{3}\right)$ \\
\hline c & centi $\left(10^{-2}\right)$ \\
\hline $\mathrm{m}$ & milli $\left(10^{-3}\right)$ \\
\hline$\mu$ & micro $\left(10^{-6}\right)$ \\
\hline $\mathrm{n}$ & nano $\left(10^{-9}\right)$ \\
\hline Symbols a & d Abbreviations: \\
\hline diam & diameter \\
\hline deg & degree \\
\hline $\mathrm{K}$ & kelvin temperature \\
\hline${ }^{\circ} \mathrm{C}$ & Celsius temperature \\
\hline $\mathrm{J}$ & joule \\
\hline cal & calorie \\
\hline A & ampere \\
\hline$V$ & volt \\
\hline$\Omega$ & ohm \\
\hline $\mathrm{Hz}$ & Hertz \\
\hline $\mathrm{m}$ & meter \\
\hline$g$ & gram \\
\hline mol & mole \\
\hline$N$ & normal (equivalents $/ 1000 \mathrm{~cm}^{3}$ of solution) \\
\hline S & mass of sample \\
\hline s & second \\
\hline $\min$ & minute \\
\hline h & hour \\
\hline $\mathrm{Pa}$ & Pascal, N/m ${ }^{2}, \sim 1.33 \times 10^{2} \mathrm{~mm} \mathrm{Hg}$ \\
\hline $\begin{array}{l}\text { psi } \\
\text { hp }\end{array}$ & pounds per square inch \\
\hline hp & horsepower \\
\hline ac & alternating current \\
\hline dc & direct current \\
\hline rms & root mean square \\
\hline rpm & revolutions per minute \\
\hline No., \# & number \\
\hline$\%$ & percent \\
\hline sdm & standard deviation of the mean \\
\hline$k$ & proportionality factor for heat leak \\
\hline Cat. & catalog \\
\hline Ser. & serial \\
\hline C.A.T. & current-adjusting-type control unit \\
\hline PTFE & polytetrafluoroethylene \\
\hline CVC & Consolidated Vacuum Corporation \\
\hline $\mathrm{H}-\mathrm{P}$ & Hewlett-Packard \\
\hline $\mathrm{L}$ and $\mathrm{N}$ & Leeds and Northrup Compariy \\
\hline M-H & $\begin{array}{l}\text { Minneapolis-Honeywell Regulator } \\
\text { Company }\end{array}$ \\
\hline
\end{tabular}

\section{References}

[1] Nuttall, R. L., Laufer, A. H., and Kilday, M. V., J. Chem. Thermodynamics 3, 167 (1971).

[2] Gunn, S. R., J. Phys. Chem. 69,2902 (1965).

[3] Parker, V. B., Thermal Properties of Aqueous Uni-univalent Electrolytes, Nat. Stand. Ref. Data Ser., Nat. Bur. Stand. (U.S.), 2, 66 pages (April 1965).

[4. Cameron, A. E. and Wichers, E., J. Am. Chem. Soc. 84, 4175 (1962). 
[5] Commission on Atomic Weights, Pure and Applied Chem. 21 , 91 (1970).

[6] Gunn, S. R., J. Chem. Thermodynamics 2, 535 (1970).

[7] Nat. Bur. Stand. (U.S.) Certificate, Standard Reference Material 1654, $\alpha$-Quartz, for Hydrofluoric Acid Solution Calorimetry, Washington, D.C. 20234, April 7, 1971.

[8] Kilday, M. V., and Prosen, E. J., J. Res. Nat. Bur. Stand. (U.S.), 77A (Phys. and Chem.), No. 2, 205-215 (Mar.-Apr. 1973).
[9] Nat. Bur. Stand. (U.S.) Certificate, Standard Reference Material 724 for Solution Calorimetry, tris(hydroxymethyl) aminomethane, Washington, D.C., 20234, April 14, 1972.

[10] Kilday, M. V., Prosen, E. J., and Wagman, D. D., J. Res. Nat. Bur. Stand. (U.S.), 77A (Phys. and Chem.), No. 2, 217-235 (Mar.-Apr. 1973).

(Paper 77A2-762) 